\title{
Evolving Views on the Pallium
}

\author{
Loreta Medina Antonio Abellán Ester Desfilis \\ Department of Experimental Medicine, Faculty of Medicine, University of Lleida, Lleida's Institute for \\ Biomedical Research - Dr. Pifarré Foundation (IRBLleida), Lleida, Spain
}

\section{Keywords}

Forebrain · Morphoplan · Developmental units · Evodevo ·

Field homology · Cell homology · Gene regulatory networks ·

Transcription factors · Convergence · Divergence

\begin{abstract}
The pallium is the largest part of the telencephalon in amniotes, and comparison of its subdivisions across species has been extremely difficult and controversial due to its high divergence. Comparative embryonic genoarchitecture studies have greatly contributed to propose models of pallial fundamental divisions, which can be compared across species and be used to extract general organizing principles as well as to ask more focused and insightful research questions. The use of these models is crucial to discern between conservation, convergence or divergence in the neural populations and networks found in the pallium. Here we provide a critical review of the models proposed using this approach, including tetrapartite, hexapartite and double-ring models, and compare them to other models. While recognizing the power of these models for understanding brain architecture, development and evolution, we also highlight limitations and comment on aspects that require attention for improvement. We also discuss on the use of transcriptomic data for understanding pallial evolution and advise for better contextual-
\end{abstract}

ization of these data by discerning between gene regulatory networks involved in the generation of specific units and cell populations versus genes expressed later, many of which are activity dependent and their expression is more likely subjected to convergent evolution.

(c) 2021 S. Karger AG, Base

\section{Introduction}

Brain models are conceptual frameworks that represent the basic structural units and subunits of the organ, which help to better understand its neural architecture (at cellular, molecular and circuit levels) and function, and to make predictions on the system in health and disease. Models are also critical to compare the basic units/subunits across species independently of deformations and variations due to their divergent morphogenesis [Nieuwenhuys, 1998a, c; Puelles, 2009]. Currently, it is more crucial than ever to count with a good brain model that helps to compare brain divisions across species and to discern between conservation, divergence and convergence in evolution, given the current renewed interest in increasing the diversity of species in neuroscience. This interest aims to improve our understanding of general organizing principles that may also apply to humans and 
can help to address better questions concerning mechanisms behind brain development, function and dysfunction [Preuss, 2000; Striedter et al., 2014; Hale, 2014, 2019; Bolker, 2019; Striedter, 2019].

A good model should consider topological coordinates, which are invariant independently of deformations, and organize units across rostrocaudal and dorsoventral axes [Nieuwenhuys et al., 1998a, b; Nieuwenhuys and Puelles, 2016]. The best way to identify the basic brain units shared by different species is through comparative neuroembryology studies [Holmgren, 1922; Bergquist, 1932; Källén, 1951, 1953; Puelles et al., 1987; Striedter, 1997; Nieuwenhuys et al., 1998a, c; Puelles and Medina, 2002; Nieuwenhuys and Puelles, 2016]. Early comparative neuroembryologists provided evidence for the existence of distinct proliferative centers along the rostrocaudal and dorsoventral axes of the neural tube, separated by borders exhibiting minimal proliferation [Rendahl, 1924; Vaage, 1969], and they defined developmental units as migration areas associated to each proliferative zone [Bergquist and Källén, 1953, 1954; reviewed by Nieuwenhuys et al., 1998a; Nieuwenhuys and Puelles, 2016; Nieuwenhuys, 2017]. Since cell migration into the mantle in each unit primarily occurs radially, often following radial glial fibers, this led to the definition of radial histogenetic units [Nieuwenhuys et al., 1998b; Puelles and Medina, 2002; Nieuwenhuys and Puelles, 2016].

Comparative neuroembryology has experienced a rebirth in the context of the evolutionary developmental (evodevo) neurobiology, thanks to studies of expression patterns of highly conserved regulatory genes in the embryonic brain of different species, which allowed visualization of the basic developmental units during embryonic development [Shimamura et al., 1997; Puelles et al., 2000; Murakami et al., 2001, 2005; González et al., 2002a, b; Bachy et al., 2001, 2002a, b; Mueller and Wullimann, 2002; Wullimann and Mueller, 2002, 2004; Wullimann et al., 2005; Brox et al., 2003, 2004; Kitagawa et al., 2004; Moreno et al., 2004, 2008a, b, 2010, 2012; Mueller et al., 2006, 2008; Eaton et al., 2008; Ferran et al., 2007, 2009, 2015; Abellán and Medina, 2009; Abellán et al., 2009, 2010, 2014; Osório et al., 2010; Domínguez et al., 2010, 2013; Morona et al., 2011; Quintana-Urzainqui et al., 2012, 2015; Affaticati et al., 2015; Ganz et al., 2014; Sugahara et al., 2016; Desfilis et al., 2018; Porter and Mueller, 2020]. Early expressed regulatory genes encode transcription factors and signaling proteins, which play key roles in patterning, specification, proliferation, or differentiation, and their expression patterns are highly similar across species at early "phylotypic" embryonic stages [reviewed by Puelles and Medina, 2002; Mueller et al., 2006; Medina, 2007; Osório et al., 2010]. These gene expression studies corroborated some of the developmental units and boundaries described previously [reviewed by Nieuwenhuys and Puelles, 2016], but turned out to be more powerful, especially in the brain region showing the highest complexity, the forebrain.

The combinatorial expression patterns of early regulatory genes, analyzed in the context of their position within the topological framework of the neural tube, helped to better define the building plan (Bauplan) or morphoplan of the brain, and these studies became extremely useful to identify the same (homologous) units in different species [Puelles and Medina, 2002; Medina, 2007; Puelles and Ferran, 2012]. This led to the coining of a new term, "genoarchitecture," to refer to gene expression with respect to the topological framework [Ferran et al., 2009; Puelles and Ferran, 2012]. Genoarchitecture, together with fate mapping and other relevant data, has become an essential criterion for the definition of the "fundamental morphogenetic units" (FMUs) of the brain, whose development is regulated by specific networks and cascades of regulatory genes expressed within the units. This also underlies the proposal of "a new neuromorphology" based on those fundamental units, by Nieuwenhuys and Puelles [2016] [see also Nieuwenhuys, 2017]. The FMUs are initially established in the embryonic neural tube at the neuroepithelial level, but soon transform into 3D radial units, where locally generated neurons primarily migrate and differentiate (except in cases of tangential migrations); thus, these units established during embryonic development are behind the adult brain organization [Puelles and Medina, 2002; Nieuwenhuys and Puelles, 2016]. The link between FMUs to the divisions and neuron populations found in the adult brain has been revealed by experimental fate mapping in numerous studies [for example, Marín and Puelles, 1995; García-López et al., 2004], but this is becoming easier to analyze thanks to the generation of transgenic reporter animals that make it possible to trace gene-specific lineage cells from particular embryonic divisions into the adult brain and to study their mature phenotype and connections [for example, DiBonito et al., 2017].

Results from these different studies supported the long ago proposed, and later ignored, neuromeric model: i.e., the neural tube is divided, like in a checkerboard, into transverse units or neuromeres, superimposed to several longitudinal zones that run from rostral to caudal [reviewed by Puelles, 2009; Nieuwenhuys and Puelles, 2016]. 
In contrast, they defeated the so-called columnar model [Herrick, 1910; Kuhlenbeck, 1973]. Briefly, the columnar model relied on the functional organization of the mature brain, trying to extend the sensory and motor columns found in the hindbrain into the forebrain, but without considering the curvature of the longitudinal axis, leading to the erroneous conception that the epithalamus, "dorsal thalamus," "ventral thalamus" and hypothalamus are organized from dorsal to ventral [reviewed by Puelles, 2009; Nieuwenhuys and Puelles, 2016]. Although defenders of the columnar model thought that the parcellation proposed by the neuromeric model was irrelevant for understanding the functional organization of the brain, this is far from being true. During development, the molecular zones and borders highlighted by genoarchitecture are also followed by early growing axons [Shimamura et al., 1995], which form checkerboard-like scaffolds that precede the formation of the adult connectome [Nieuwenhuys and Puelles, 2016].

The work of Luis Puelles and collaborators was of paramount importance to better understand the most complex and divergent brain region, the forebrain. Based on comparative and developmental genoarchitecture, together with fate mapping, Puelles and his colleagues proposed a new model of forebrain organization, called the prosomeric model [Puelles and Rubenstein, 1993, 2003, 2015]. This model provides a reference framework for better understanding the organization of cell masses, the patterns of geno- and chemoarchitecture within the adult forebrain, and the trajectory followed by axonal tracts [Puelles, 2009; Nieuwenhuys and Puelles, 2016]. The model also helps to identify critical checkpoints during cellular tangential migration and axonal navigation, and to predict possible places for molecular changes during vertebrate evolution in cases of observed divergence (for example, the strong asymmetry in the habenulo-interpeduncular projection observed in anamniotes, but not in amniotes, and the defasciculation of its axons that enter prosomere 3 in the chicken [Puelles et al., 2019b], instead of forming a compact bundle travelling in the caudal part of prosomere 2 like in other vertebrates, resemble some of the defects seen in mutants involving genes of different guidance molecules, and are likely related to modifications that affect navigation through midline, alar-basal and/or interprosomeric boundaries [Moreno-Bravo et al., 2016; Luis Puelles, communication at the ECCN-2019 meeting in Murcia]. In addition, the prosomeric model helps to better understand brain alterations that occur following downregulation or upregulation of specific genes (due to mutation or other problems), and it constitutes an excellent reference to better understand the causal mechanisms behind brain development and evolution [Puelles and Medina, 2002; Medina, 2007; Puelles, 2009]. The proposal of the prosomeric model, initially based mostly on work in amniotes, also opened the venue to clarifying the forebrain in anamniotes, wherein the excellent contributions by Agustín González and his team stand out [González et al., 2002a, b, 2014; González and Northcutt, 2009; Moreno et al., 2004, 2008a, b, 2010, 2012; Domínguez et al., 2010, 2013; Morona et al., 2011].

One important aspect about brain models is that they should adjust to new findings [Puelles, 2009]. In fact, the prosomeric model is a living framework that has been adjusted over time to incorporate new data [Puelles and Rubenstein, 1993, 2003, 2015]. Moreover, model proponents should be prepared to include possible variations in unit or subunit number throughout vertebrate evolution, most likely in subdivisions following secondary or subsequent regionalization [see critical review by Striedter and Northcutt, 2020], as it is accepted to have happened in the transition from early chordates/protochordates to vertebrates [Northcutt, 2012; AlbuixechCrespo et al., 2017]. In the following section, we will revise possible variations of the current prosomeric model focused on the telencephalon. This should not be seen as a demerit of the model undergoing modification, but as an opportunity to improve its value as an explanatory and predictive tool.

\section{Models of Telencephalon}

Within the forebrain, the telencephalon is the largest and most divergent structure, and comparison of its subdivisions across species is still subject to great controversies. Moreover, there is no consensus on a divisional model of the telencephalon. Thus, many aspects of its evolution remain controversial. In contrast to the columnar model, the prosomeric model proposes that the rostralmost part of the neural tube is the hypothalamus [ $\mathrm{Pu}-$ elles, 2009; Puelles and Rubenstein, 2015] (Fig. 1a). This is based on the observation of a sharp bending of the longitudinal axis at rostral levels of the neural tube during development, dragging the rostral end of the tube down (Fig. 1b) [Shimamura et al., 1995, 1997; Puelles, 2009; the rostral end of the tube includes the acroterminal division, described by Puelles et al., 2012]. In this view, the telencephalon develops dorsal to the hypothalamic primordium. Both, together with the eye vesicle, develop from the 


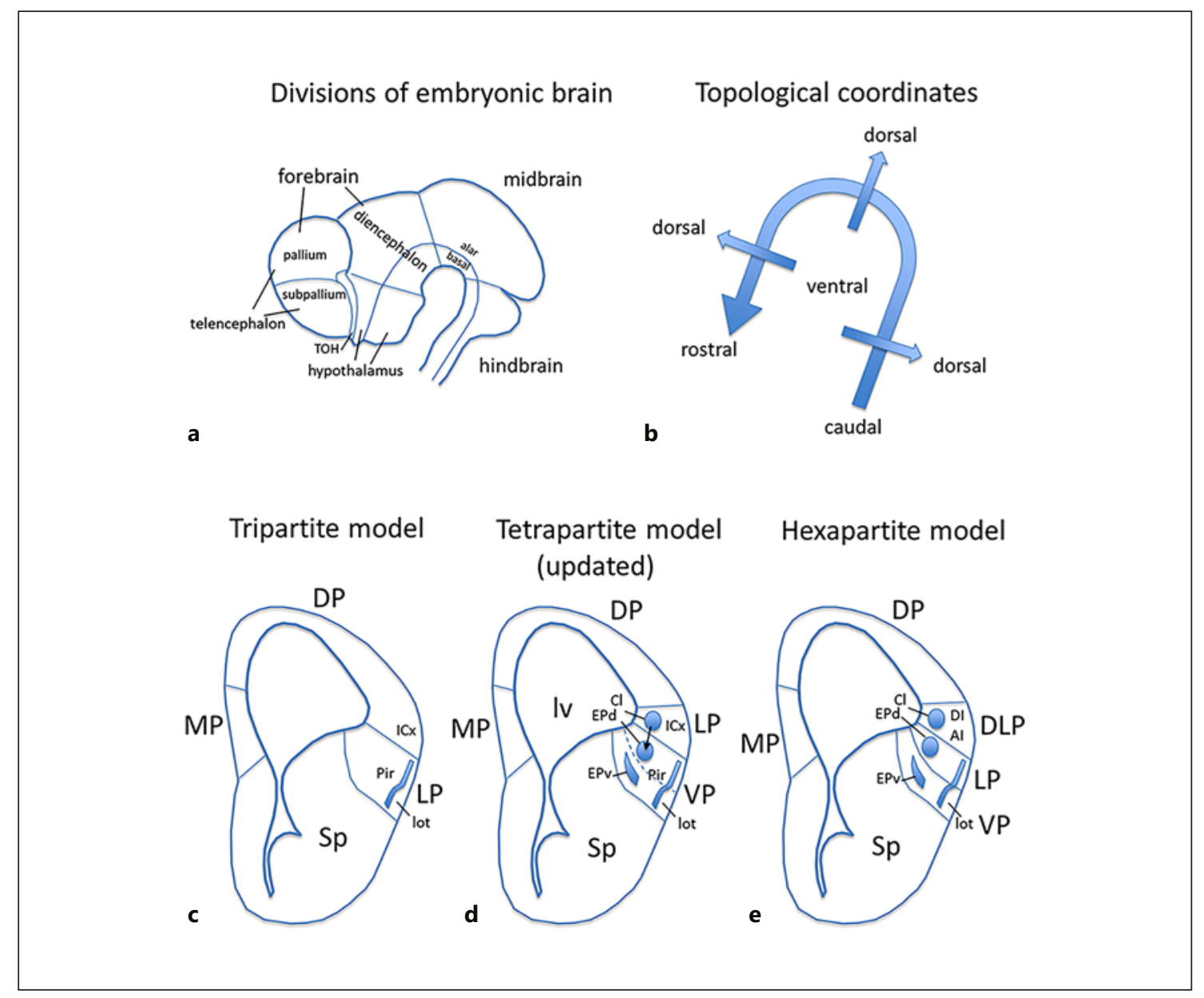

Fig. 1. a Scheme of a lateral view of the mouse embryonic brain, representing some of its major divisions and subdivisions (special focus on the forebrain or prosencephalon). The telencephalon is the dorsalmost part of the secondary prosencephalon and includes the pallium, the subpallium and the telencephalon-optohypothalamic domain ( $\mathrm{TOH})$; the latter is a newly described division located at the transition between telencephalon and hypothalamus, which shows mixed molecular features such as coexpression of Foxg1 and Otp transcription factors (TFs), but does not express the typical TFs found in the pallium (such as Emx1/2 and Neurod6) or the subpallium (such as Dlx2/5 and Nkx2.1) [Morales et al., 2021]. b Representation of the topological coordinates in an embryonic brain (like that represented in a). Note the highly bent longitudinal (rostrocaudal) axis, which takes the rostral pole down

"secondary prosencephalon," which is rostral to the diencephalic vesicle that produces the thalamus. In most models, including the prosomeric model, the telencephalon is divided into a pallium and a subpallium (Fig. 1a), which are found in all vertebrates [Reiner, 1991; Butler, 1994; Northcutt and Kaas, 1995; Striedter, 1997; Puelles, 2001; Medina and Abellán, 2009]. However, there is no [the acroterminal divison is described at the rostralmost end by Puelles et al., 2012]. c-e Schemes of frontal sections of the mouse embryonic telencephalon, which show pallial divisions according to the tripartite, tetrapartite (updated version [Puelles, 2017; Puelles et al., 2017]) or hexapartite pallial models [Medina et al., 2017b, 2019; Desfilis et al., 2018]. The hexapartite model also includes a ventrocaudal division, not represented here (but see Fig. 2). See text for more details. AI, agranular insular cortex; $\mathrm{Cl}$, claustrum; DI, dysgranular insular cortex; DLP, dorsolateral pallium; DP, dorsal pallium; EPd, endopiriform nucleus, dorsal part; $\mathrm{EPv}$, endopiriform nucleus, ventral part; ICx, insular cortex; lot, lateral olfactory tract; LP, lateral pallium; lv, lateral ventricle; MP, medial pallium; Pir, piriform cortex; Sp, subpallium; TOH, telencephalon-optohypothalamic division; VP, ventral pallium.

consensus on how many subdivisions are present in the pallium and in the subpallium, and there is a recent proposal that the telencephalon may extend beyond and include an additional subdivision named "telencephalonoptohypothalamic domain" (TOH in Fig. 1a) [Morales et al., 2021]. In this review, we will focus on the evolving models of the pallium. 


\section{Pallium}

Classical studies considered three subdivisions in the pallium (tripartite model), named medial, dorsal and lateral pallia based on their topographical position (Fig. 1c) [reviewed by Butler, 1994; Striedter, 1997; Puelles, 2001, 2017]. Many studies tried to identify these three pallial divisions in different vertebrates, but due to the extremely divergent evolution of the telencephalon, this task was far from easy [reviewed by Reiner et al., 2004; Jarvis et al., 2005]. The major problem derived from the fact that most of the pallium in non-mammals is non-laminated, and in sauropsids includes a large nuclear structure called the "dorsal ventricular ridge" (DVR), whose homology in mammals is still being debated [as discussed by Reiner et al., 2004; Jarvis et al., 2005; Stacho et al., 2020]. Candidates for homology include: a lateral part of the neocortex [Reiner, 1991; Butler, 1994]; cell populations of specific neocortical layers [Karten, 1997; Dugas-Ford et al., 2012; Briscoe et al., 2018]; claustrum, endopiriform nuclei and/ or basal complex of the amygdala [Bruce and Neary, 1995; Puelles et al., 2000, 2017; Puelles, 2001; Martínez-García et al., 2002, 2007; Medina and Abellán, 2009; Medina et al., 2011; 2017a; Desfilis et al., 2018; Tosches et al., 2018].

As noted above, it is at early developmental stages when the brain of different animals shows more clearly its Bauplan or morphoplan, turning easier comparison and identification of homologous divisions (field homology), while species differences appear during late development [Puelles and Medina, 2002; Medina, 2007]. Below we will review and discuss some of the models proposed based on comparative embryonic developmental studies, starting with the four-part or tetrapartite pallial model, continuing with the six-part or hexapartite pallial model and finishing with the double-ring pallial model (in chronological order).

\section{Tetrapartite Pallial Model}

Using comparative embryonic genoarchitecture in the mouse and chicken, Puelles and colleagues proposed that the pallium in amniotes includes not three, but four divisions (tetrapartite pallial model), implying the subdivision of the classical lateral pallium in two and the definition of a new "ventral pallium," just above the palliosubpallial boundary [Puelles et al., 2000; Puelles, 2001; an updated version of the model is represented in Fig. 1d]. The new ventral pallial sector was initially defined in the mouse and chicken by expression of panpallial regulatory

Evolving Views on the Pallium transcription factors such as Pax6 and Tbr1, but lack of expression in the ventricular zone of Emxl (typical in other pallial sectors) and Dlx2 (typical in the subpallium) [Puelles et al., 2000]. Emx1, its paralog Emx2, and Pax6 are expressed in opposite gradients in the pallium and play critical roles in its patterning and area specification [Bishop et al., 2002, 2003; Muzio et al., 2002; Muzio and Mallamaci, 2003], while Tbr1 is essential for the differentiation of glutamatergic pallial cells [Hevner et al., 2001]. The combinatorial gene expression of Emx1, Pax6 and Tbr1 was initially used to identify the ventral pallium in the anuran Xenopus laevis [Bachy et al., 2002b; Brox et al., 2003, 2004] and lampreys [Murakami et al., 2001], suggesting that this division is present in all vertebrates. Later, some transcription factors were found to be distinctly expressed in the ventral pallium, such as Dbx1 in the ventricular zone [Yun et al., 2001; Medina et al., 2004] and Lhx9 in the intermediate zone and mantle [García-López et al., 2008; Abellán et al., 2009]. While Dbx1 defines the ventricular zone of the ventral pallium in the mouse, this gene is not expressed in the ventral pallium of non-mammals [Bielle et al., 2005; reviewed by Medina et al., 2017b]. In contrast, Lhx9 has been found in the ventral pallium of mice [García-López et al., 2008], chickens [Abellán et al., 2009], lacertid lizards [Desfilis et al., 2018], amphibians [Moreno et al., 2004; Moreno and González, 2006], and teleost and cartilaginous fishes [Peukert et al., 2011; Quintana-Urzainqui et al., 2015]. Thus, the ventral pallium has been incorporated as a basic division of the vertebrate pallium, and is identified or mentioned for discussion by authors from different neuroscience ambits and employing different species, including humans [in addition to references above, see for example: Wullimann and Mueller, 2004; Lindsay et al., 2005; Mueller and Wullimann, 2009; Belgard et al., 2013; Ganz et al., 2014; Tosches et al., 2018; Porter and Mueller, 2020; Colquitt et al., 2021; Gedman et al., 2021].

According to the tetrapartite pallial model, in mammals the medial pallium gives rise to the hippocampal formation of the adult brain, the dorsal pallium produces the neocortex, while the lateral and ventral pallia produce distinct parts of the claustrum, endopiriform nuclei, piriform cortex and pallial amygdala [Puelles et al., 2000; Medina et al., 2004]. In the updated version of the model (Fig. 1d), in mammals the lateral pallium produces the insular claustrum and insular cortex, but it does not produce any part of the piriform cortex and the pallial amygdala, while the ventral pallium produces the endopiriform/piriform region (with the exception of a group of migrated cells of the dorsal endopiriform nucleus; migra- 
tion represented with an arrow in Fig. 1d) and the pallial amygdala [Puelles et al., 2017; Puelles, 2017, 2021].

One consequence of these studies is that when we compare across species the derivatives of the embryonic pallial fields, the following homology proposals come out (for simplicity, here we only mention mammals and birds, but corresponding areas are also found in reptiles, so they are likely inherited from the amniote ancestor): (1) the mammalian hippocampal formation and the avian hippocampus and parahippocampal area are homologous as medial pallial derivatives; (2) the mammalian neocortex and the avian Wulst (hyperpallium) are homologous as dorsal pallial derivatives; (3) the mammalian claustrum and insular cortex are homologous to the avian mesopallium as lateral pallial derivatives; (4) the mammalian endopiriform/piriform region and pallial amygdala are homologous to the avian nidopallium and arcopallium as ventral pallial derivatives [Puelles et al., 2016a, 2017; Puelles, 2017].

This proposal agreed with some of the conclusions of classical comparative neuroembryologists [Holmgren, 1925; Striedter, 1997] and was followed by many authors using embryonic genoarchitecture to identify homologies. For example, the homology between the mammalian hippocampal formation, the avian hippocampus and parahippocampal area, and the reptilian medial, dorsomedial and dorsal cortices was supported by their topological position next to the choroid tela and their common expression of the transcription factors Lhx2, Lhx9 and Lef1 during development, plus Prox1 in the dentate gyrus-like area that remains through adulthood [Gupta et al., 2012; Abellán et al., 2014; Medina et al., 2017a; Desfilis et al., 2018; Tosches et al., 2018]. Some of these genes were also found in the medial pallium of anamniotes [for example, Moreno et al., 2004; Ganz et al., 2014]. Moreover, experimental studies demonstrated the critical role of these genes in the development of the mammalian hippocampal formation [Lhx2: Porter et al., 1997; Bulchand et al., 2001; Lef1: Galceran et al., 2000; Prox1: Lavado et al., 2010; reviewed by Medina et al., 2017a]. Thus, they seem to represent architect genes [term coined by Ferrán, 2017] of this medial pallial structure in different vertebrates. Some of the results on comparative embryonic genoarchitecture gave support to the DVR-pallial amygdala homology hypothesis, by identifying a ventral pallial-derived mantle area with distinctive expression Lhx9 in different vertebrates [Moreno et al., 2004; Abellán et al., 2009; Desfilis et al., 2018]. Both also share distinct expression of the transcription factor Nr2f2/COUP-TF2 [Chen et al., 2013; Allen Developing Mouse Brain Atlas], which is known to be critical for mouse amygdala formation [Tang et al., 2012]. Neither Lhx9 nor Nr2f2/COUP-TF2 are expressed in lateral and dorsal pallial divisions (with the exception of subsets of immigrant cells). But although derived from the same embryonic domain and showing some similarities, DVR and pallial amygdala also differ in many respects, as evidenced by results of a whole-cell transcriptome in adults [Belgard et al., 2013; see further discussion below]. Moreover, a recent study in the mouse by García-Calero et al. [2020] showed that the pallial amygdala derives from a pallial sector caudal to that producing the endopiriform/piriform region, and it should be considered a pallial division different from the ventral pallium. In addition, some of the regulatory genes expressed in the ventricular zone of the ventral pallium of the mouse (in particular, Dbx1 and Sfrp2) are not found in the ventral pallium of sauropsids [Dbx1: Bielle et al., 2005; Sfrp2: A. Abellán, unpubl. results]. We will come back to this issue below.

\section{Hexapartite (Six-Part) Pallial Model and Comparison to the Tetrapartite Model}

When trying to identify four pallial divisions in the telencephalon of different amniotes (chicken, long-tailed lacertid lizard and mouse) using combinatorial gene expression patterns during embryonic development, we found that the tetrapartite model was insufficient, making difficult the comparison of pallial areas such as the entorhinal cortex of mammals or the arcopallium of birds [Abellán et al., 2014; Medina et al., 2017a, b]. In addition, it could not explain the existence of a posterior pole of the mouse pallial amygdala poor in Dbx1-lineage cells [Puelles et al., 2016b] and having a different molecular profile to that typical of the ventral pallium [discussed by Medina et al., 2017b]. After a comparative embryonic genoarchitecture analysis, we proposed a new pallial model: the hexapartite model (Fig. 1e, 2a). The major difference with the tetrapartite model concerns the number of fundamental units found in the embryonic pallium, some of their derivatives, and how we compare these units between amniotes. The hexapartite pallial model proposes the existence of medial, dorsal, dorsolateral, lateral, ventral and ventrocaudal sectors [Medina et al., 2017b, 2019; Desfilis et al., 2018]. At rostrointermediate levels, these distinct pallial sectors show alternate expression of Lhx9 (expressed in the medial pallium, dorsolateral pallium, and ventral pallium, but not in the dorsal pallium and lateral pallium) [Abellán et al., 2009; Desfilis et al., 2018]. 


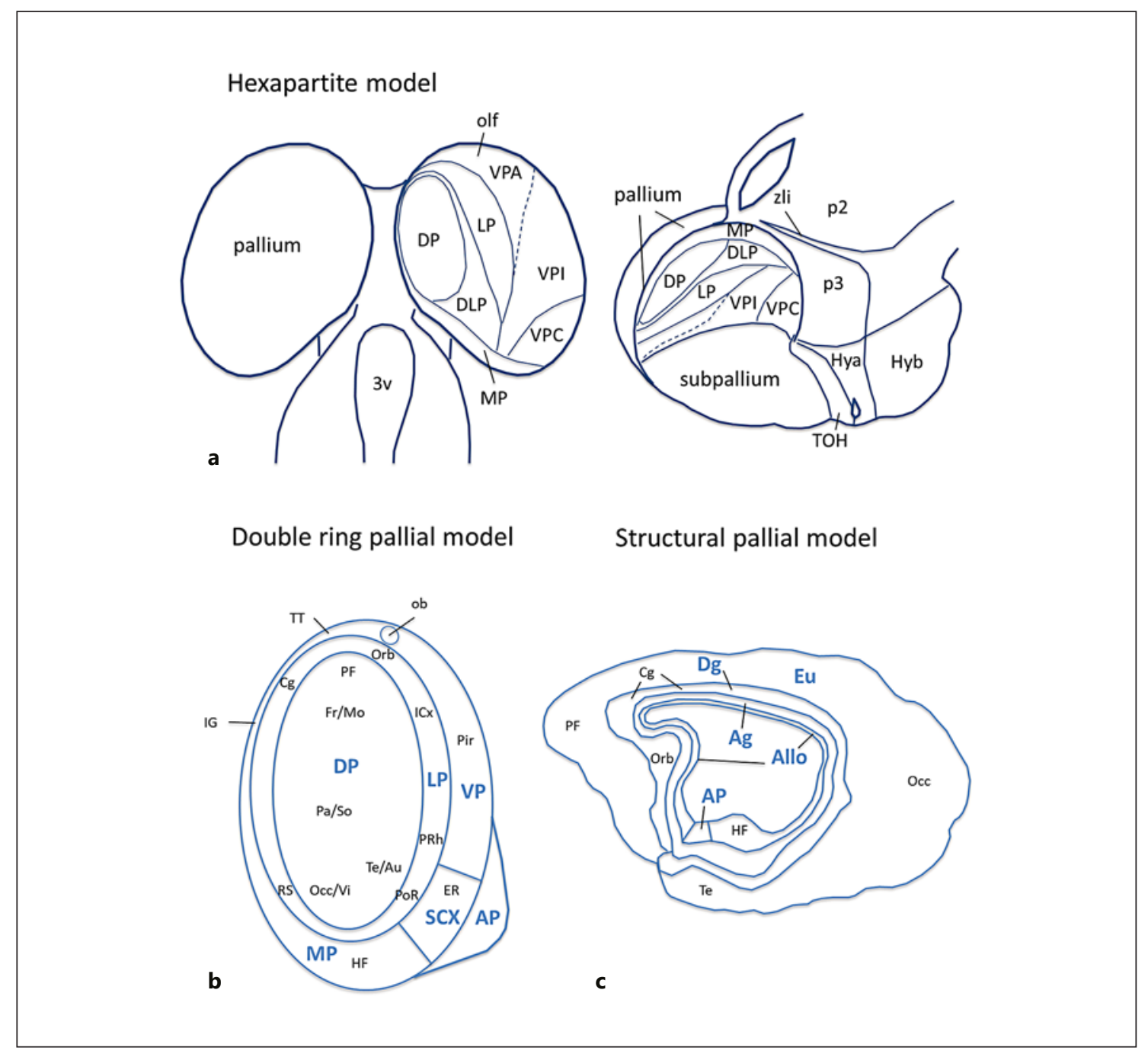

Fig. 2. a Schematic representation of pallial divisions and some subdivisions according to the hexapartite model, as seen in dorsal (left) or lateral (right) views of the chicken embryonic forebrain (all divisions are shown in both schematic views, although not all are seen at the same time). In this version of the hexapartite model, the ventral pallium was subdivided into anterior and intermediate parts, to distinguish two major radial subdivisions of this pallial division in birds and facilitate their comparison to corresponding subdivisions in mammals and other vertebrates. In birds, the intermediate subdivision includes the so-called intercalated nidopallium [name coined by Jarvis et al., 2013], a distinct radial sector that includes the sensory nuclei from caudal to rostrolateral levels. In the mouse, the comparable pallial sector may include the sensory nuclei of the pallial amygdala. b, c Schematic representation of pallial divisions according to the double-ring [Puelles et al., 2019a] or the structural models [García-Cabezas et al., 2019], in dorsal, flattened (left) or medial (right) views of the pallium. Major divisions are shown in larger, bold font. For orientation, frontal and occipital poles of the cortex are indicated. So far, these models only apply to mammals. See text for more details. Ag, agranular cortex; AI, agranular insular cortex; Allo, allocortex; AP, amygdala, pallial part; $\mathrm{Au}$, auditory cortex; $\mathrm{Cg}$, cingulate cortex; $\mathrm{Cl}$, claustrum; Dg, dysgranular cortex; DI, dysgranular insular cortex; DLP, dorsolateral pallium; DP, dorsal pallium; EPd; endopiriform nucleus, dorsal part; EPv, endopiriform nucleus, ventral part; ER, entorhinal cortex; Eu, eulaminar cortex; Fr, frontal cortex; HF, hippocampal formation; Hya, hypothalamus, alar part; Hyb, hypothalamus, basal part; ICx, insular cortex; IG, indusium griseum; lot, lateral olfactory tract; LP, lateral pallium; Mo, motor cortex; MP, medial pallium; Occ, occipital cortex; ob, olfactory bulb; olf, olfactory pallial areas; Orb, orbitofrontal cortex; p2, prosomere 2; p3, prosomere 3; Pa, parietal cortex; PF, prefrontal cortex; Pir, piriform cortex; PoR, postrhinal cortex; PRh, perirhinal cortex; RS, retrosplenial cortex; SCX, schizocortex; So, somatosensory cortex; Te, temporal cortex; $\mathrm{TOH}$, telencephalon-optohypothalamic division; TT, taenia tecta; Vi, visual cortex; VP, ventral pallium; VPA, VP, anterior subdivision; VPI, VP, intermediate subdivision; VPC, ventrocaudal pallium; zli, zona limitans intrathalamica; $3 \mathrm{v}$, third ventricle. 
This alternate expression pattern is evident at early stages in sauropsids, but later the expression is downregulated in a large part of the ventral pallium, remaining only in the olfactory bulb and posterior (pallial amygdala-like) parts of the DVR, just as it occurs in the mouse [for the mouse, see Abellán et al., 2009, and a recently revised analysis by García-Calero and Puelles, 2021]. In addition, each division shows a characteristic gene expression profile during development. The embryonic medial pallium is rich in Lhx2, Lhx9, Lef1 and Lmo4, and based on this it was proposed to include not only the hippocampal formation but also the medial entorhinal cortex in mouse, and corresponding areas in sauropsids [Abellán et al., 2014; Medina et al., 2017a; Desfilis et al., 2018]. Moreover, the medial pallium of mammals and sauropsids includes a dentate gyrus-like subdivision characterized by expression of Prox1 [Gupta et al., 2012; Dugas-Ford et al., 2012; Abellán et al., 2014; Tosches et al., 2018]. At early embryonic stages, the dorsal pallium is rich in Lhx2 but poor in Lhx9 and Lef1, and includes the avian hyperpallium or Wulst [Abellán et al., 2009, 2014] and a corresponding small area in the rostromedial pallium of lizards [Desfilis et al., 2018; see also Hoops et al., 2018].

One important difference with the tetrapartite model is the definition of a new pallial sector, the dorsolateral pallium, interposed between dorsal and lateral pallia (Fig. 1d, e, 2a, b). In sauropsids, the dorsolateral pallium locates above the DVR and differs from it because the latter is rich in Lmo3 expression from early embryonic stages, while the dorsolateral pallium is poor in Lmo3 [Abellán et al., 2014; Desfilis, 2018; Medina et al., 2017a, b, 2019]. The dorsolateral pallium also differs from the dorsal pallium by its expression of Lhx9. Moreover, the dorsolateral pallium shows distinct expression of cadherin 8 (Cdh8) and cerebellin 2 (Cbnl2) [Medina et al., 2019; for Cbln2, see also Reiner et al., 2011]. Based on these features, in chickens the dorsolateral pallium gives rise to a pallial sector located lateral (mostly caudolateral) to the Wulst and dorsal to the mesopallium. This pallial area has been identified with different names in birds, such as caudodorsolateral pallium [CDL in Puelles et al., 2007; Belgard et al., 2013] or caudal hyperpallium [HC in Puelles et al., 2019b]. In mammals, the same division appears to produce the claustroinsular region (insular claustrum plus overlapping agranular/dysgranular insular cortex), the perirhinal cortex and the lateral entorhinal cortex [Abellán et al., 2014; Medina et al., 2017a, b; 2019; Desfilis et al., 2018]. Like the avian dorsolateral pallium, the claustroinsular region and perirhinal cortex of mouse occupy an Lmo3-poor area intercalated between the lateral/ ventral pallia (endopiriform/piriform region) and the dorsal pallium (neocortex) [Tole et al., 2005; Abellán et al., 2009], and show expression of Cdh8 and Cbnl2 [Medina et al., 2019]. Based on topological continuity with the perirhinal cortex and their similar cytoarchitecture, we proposed that the lateral entorhinal cortex also derives from the dorsolateral pallium. This agrees with data on enhancers driving gene expression in different cortical sectors in the mouse, showing continuity from orbitofrontal cortex (see below) through claustroinsular region, perirhinal cortex and lateral entorhinal cortex [for example, enhancer 671 in Pattabiraman et al., 2014]. However, we differ with the tetrapartite model regarding where a claustroinsular-like region is located in birds: Puelles and colleagues considered that it is the mesopallium [Puelles, 2017; Puelles et al., 2017], while we proposed that it is above the mesopallium, in the division we defined as the avian dorsolateral pallium [Desfilis et al., 2018]. Puelles et al. [2016a] identified a homologue of the claustrum in a population of Nr4a2-expressing cells in the avian mesopallium, but it should be noted that this gene is expressed in both the mesopallium and the dorsolateral pallium from early developmental stages (see further discussion in the transcriptome section below). In our opinion, the superficial area identified as claustrum by Puelles et al. [2016a] is part of the dorsolateral pallium. Interestingly, a recent study on a single-cell transcriptome of early developing cortical areas in the mouse found a gradiental distribution in the expression of transcription factors from ventral to dorsal, leading to a partition model [Moreau et al., 2021] similar to that proposed in the hexapartite model. In particular, Moreau et al. [2021] described two divisions in the lateral pallial region, interposed between the ventral pallium and the dorsal pallium, which they called LP1 and LP2; these resemble the lateral pallium and dorsolateral pallium, respectively, of the hexapartite model.

In reptiles, the dorsolateral pallium produces the area of the lateral cortical superposition (where the lateral cortex overlaps the dorsal cortex and, at rostral levels, the lateral part of the pallial thickening) [Desfilis et al., 2018]. Based on their apparent similar origin, we compared the reptilian lateral cortical superposition to the claustroinsular cortex and, more caudally, the lateral entorhinal cortex of mammals [Medina et al., 2017a; Desfilis et al., 2018]. Our identification of the rostral lateral cortical superposition of reptiles in the same pallial division that produces the claustroinsular region of mammals [Desfilis et al., 2018] agrees with homology proposals of Puelles [Puelles, 2017; Puelles et al., 2017] and Tosches et al. 
[2018]. Regarding the comparison of the lizard lateral cortical superposition (at intermediate/caudal levels) with the mammalian lateral entorhinal cortex, in addition to their apparent similar origin, both exhibit a superficial cell layer with reelin expression, which remains high postnatally and seems to give rise to similar perforant-like projections [discussed by Medina et al., 2017a]. A similar entorhinal-like area has been identified in birds at the surface of the dorsolateral pallium [discussed by Medina et al., 2017a]. However, Puelles et al. [2019a] consider that the entorhinal cortex derives from a separate pallial division (see below).

In the hexapartite model, we proposed that the dorsolateral pallium extends rostrally, to olfactory and postolfactory levels of the pallium, including the orbitofrontal cortex in mammals and comparable areas in sauropsids [Desfilis et al., 2018; Medina et al., 2019]. The inclusion of the orbitofrontal cortex, the claustroinsular region and the perirhinal cortex in the same pallial division, as done in the hexapartite model, agrees with the updated tetrapartite model [Puelles, 2017; see also Pattabiraman et al., 2014] as well as with the conception of the pallium as a series of concentric rings around the dorsal pallium $[\mathrm{Pu}-$ elles et al., 2019a; García-Cabezas et al., 2019; see below]. However, while Puelles et al. [2019a] consider these structures as derivatives of their lateral pallium (Fig. 1d), we interpreted them as derived from a distinct dorsolateral pallial sector, interposed between dorsal pallium and the lateral pallium (Fig. 1e) [Medina et al., 2017b; 2019; Desfilis et al., 2018]. In the hexapartite pallial model, the frontal pole of the dorsolateral pallium, which includes the orbitofrontal cortex in mammals, encompasses the laminar pallial nucleus in birds [Medina et al., 2019] and a corresponding area in reptiles [Desfilis et al., 2018]. In the mouse and chicken, this sector is poor in $\mathrm{Lmo} 3$ and rich in Cbln2 expression (typical of other parts of the dorsolateral pallium), and is reciprocally connected with the olfactory bulb/anterior olfactory nucleus, piriform cortex and pallial amygdala (or pallial amygdala-like region) [discussed by Desfilis et al., 2018; Medina et al., 2019].

The hexapartite model helps to explain the existence of three clear subdivisions in the DVR, separated by cellpoor laminae, as it occurs in boundaries between major brain divisions [Desfilis et al., 2018]. These subdivisions are the mesopallium, nidopallium and arcopallium in birds, and corresponding sectors of the DVR in reptiles, which would derive from the lateral, ventral and ventrocaudal pallia, respectively [Abellán et al., 2014; Medina et al., 2017b, 2019; Desfilis et al., 2018]. Like the corresponding divisions in the mouse, all of them express Lmo3 in

Evolving Views on the Pallium sauropsids [Abellán et al., 2009]. In addition, each sector shows a particular gene expression profile: the lateral pallium expresses Emx1, FoxP1, Satb2 and Nr4a2, but not Lhx9 and Dachshund 2 (Dach2); the ventral pallium expresses Lhx9, Nr2f2/COUP-TF2 and Dach2, but not FoxP1, Satb2 and Emx1 (except a few immigrant cells in the marginal zone); the ventrocaudal pallium expresses Lxh9, Emx1, Nr2f2/COUP-TF2 and Zic2, but not Dach2 [Puelles et al., 2000, 2016a, 2017; Abellán et al., 2009; Suzuki et al., 2012; Chen et al., 2013; Tosches et al., 2018]. These subdivisions also show distinct molecular profiles in transcriptome analysis [Belgard et al., 2013; Briscoe et al., 2018; Tosches et al., 2018; Gedman et al., 2021].

Where are the three pallial divisions producing the sauropsid DVR in mammals, and what areas do they produce? The hexapartite model proposes that the mouse lateral pallium gives rise to the dorsal endopiriform nucleus plus a dorsal part of the piriform cortex; the ventral pallium produces the ventral endopiriform nucleus, a ventral part of the piriform cortex, plus a large anterior part of the pallial amygdala; while the ventrocaudal pallium gives rise to a small posterior pole of the pallial amygdala [Medina et al., 2017b, 2019]. Like in sauropsids, derivatives of these divisions in mouse express Lmo3 during development, but differ in expression of other regulatory genes as mentioned above: Emx1, Nr4a2, FoxP1, Lhx9, Dach2, Satb2, and Nr2f2/COUP-TF2 [Puelles, 2014; Puelles et al., 2000, 2016a, 2017; Abellán et al., 2009, 2014; Tang et al., 2012; see also Allen Developing Mouse Brain Atlas and Moreau et al., 2021]. In the mouse, these divisions also differ in their expression of the transcription factor Dbx1, which is transitorily found in the ventricular zone of the ventral pallium at early embryonic stages, but is absent in the ventricular zone of the lateral and ventrocaudal pallial sectors [Yun et al., 2001; Medina et al., 2014]. Using a Dbx1-LacZ reporter mouse to study the destination of these cells, it was possible to fate map ventral pallial derivatives. Results with this reporter showed that ventral pallial Dbx1-lineage cells mostly populate the ventral endopiriform nucleus and the ventral part of the piriform cortex, as well as a large part of the pallial amygdala [Puelles et al., 2016b]; in contrast, the dorsal endopiriform/piriform region and the posterior pole of the pallial amygdala are poor in Dbx1-lineage cells [Puelles et al., 2016b]. However, since the ventral pallium of sauropsids lacks Dbx1-expressing progenitors, expression of this transcription factor seems to be a novelty in cells of the ventral pallium of mammals [reviewed by Medina et al., 2017b]. In mammals and sauropsids, the ventral pallium expresses Lhx9 [Abellán et al., 2009, 2014] and Dach2 
[Puelles et al., 2017]. Lhx9 is later restricted to a caudal part of the ventral pallium, which includes part of the caudal nidopallium in chickens, a corresponding part of the anterior DVR of lizards, and part of the anterior pallial amygdala in mice [Abellán et al., 2009, 2014; Chen et al., 2013; Desfilis et al., 2018]. These Lhx9-expressing areas of the ventral pallium of sauropsids and mammals have been suggested to be homologous [Medina et al., 2017b; Desfilis et al., 2018]. Lhx9 is also expressed in a pallial amygdala-like area of amphibians [Moreno and González, 2006], suggesting that at least these cells were present in the ventral pallium of the last common ancestor of tetrapods, if not earlier [Medina et al., 2017b].

In sauropsids and mammals, these areas of the ventral pallium also express the transcription factor $\mathrm{Nr} 2 \mathrm{f} 2 /$ COUP-TF2 [Chen et al., 2013; Tang et al., 2012; Alzu'bi et al., 2017; Allen Developing Mouse Brain Atlas]. Lack of function of Nr2f2/COUP-TF2 in the mouse leads to severe malformation of the amygdala, showing that this transcription factor plays a critical role in its development [Tang et al., 2012].

The expression of Lhx9 and Nr2f2/COUP-TF2 are particularly high in the ventrocaudal pallium, which produce the posterior part of the DVR in sauropsids [Abellán et al., 2009, 2014; Chen et al., 2013; Desfilis et al., 2018]. Importantly, Lhx9 has been found to be a hub gene in the arcopallium (posterior DVR) of birds, suggesting a relevant role of this transcription factor in this region [Gedman et al., 2021; these authors defined hub genes as those with significant expression in a given region and high connectivity to other genes in a given network]. In the hexapartite pallial model, we proposed that the ventrocaudal pallium produces the posterior pole of the pallial amygdala, which relates to a distinct posterior ventricular sector rich in expression of the transcription factors Emx1, Lhx2 and Lhx9, but lacking Dbx1 [Medina et al., 2017b]. Like the posterior DVR of turtles [Tosches et al., 2018], this posterior pole of the pallial amygdala of the mouse expresses the transcription factor Zic2 [Murillo et al., 2015; Allen Developing Mouse Brain Atlas].

Interestingly, in a recent analysis of the mouse amygdala by Puelles and colleagues, the whole pallial amygdala was shown to originate from a posterior ventricular sector different from that of the endopiriform/piriform region, leading these authors to restrict the term ventral pallium to rostral olfactory plus endopiriform/piriform region, but excluding the pallial amygdala, which is assigned to a distinct caudal division [Puelles et al., 2019a; García-Calero et al., 2020]. Moreover, they divided the pallial amygdala into five different radial units, with each unit including deep nuclei and a cortical area at the surface. Notably, the most posterior radial unit of the pallial amygdala, which produces the amygdalohippocampal transition area and the posteromedial cortical amygdalar area [García-Calero et al., 2020], resembles the ventrocaudal pallium of the hexapartite model. The new proposal on the pallial amygdala seems more powerful to explain the genoarchitecture of the mouse pallial amygdala and for comparative considerations. This reinforces the existence of radial subdomains producing different parts of the sauropsid DVR (including areas rich in Lhx9, moderate in Lhx9 or even free of Lhx9 expression of the anterior and posterior DVR), similar to those producing different parts of the pallial amygdala of mammals [as previously discussed by us in Abellán et al., 2009; Medina et al., 2011, 2017a; and Desfilis et al., 2018]. This would agree with results from a single-cell transcriptome that support homologies of the anterior and posterior DVR with different subdivisions of the pallial amygdala of mammals [Tosches et al., 2018].

\section{Double-Ring Pallial Model and Comparison to Previous Models}

Recently, Puelles et al. [2019a] proposed a new model of pallial divisions, the so-called double-ring pallial model (Fig. 2b), which is claimed to be more powerful than the previous tetrapartite and hexapartite models. This model is based on the observed transitional architecture and molecular profile of the mammalian pallium from the six-layered neocortex to the three-layered allocortices on its medial or lateral sides, represented by the hippocampal formation and the piriform cortex, respectively. This model partially resembles other proposals of mammalian cortical organization, such as that elaborated recently by García-Cabezas et al. [2019], named the "structural model," which considers not two but three rings around the six-layered cortex (Fig. 2c). According to these models, the six-layered cortex (eulaminar or granular type, based on the presence of layer 4 with granular cells) is surrounded by bands or rings of transitional dysgranular and agranular cortices, before arriving to the three-layered cortices. On the frontal side, this transitional area includes the orbitofrontal cortex (or part of it); laterally, it includes the agranular/dysgranular insular cortex and the perirhinal cortex, followed caudally by the postrhinal cortex; lastly, on the medial side, it includes the cingulate and retrosplenial cortices. This agrees with some of the proposals of the revisited tetrapartite and 
hexapartite models: in particular, the inclusion of the orbitofrontal cortex (or part of it), the agranular/dysgranular insular cortex, the perirhinal cortex and the postrhinal cortex in the same pallial type sector(s) or ring(s). This also agrees with results on enhancers driving gene expression in different cortical sectors and fate mapping of distinct enhancer-related domains in the mouse [Pattabiraman et al., 2014]. In the double-ring model, Puelles et al. [2019a] propose a revision of their previous tetrapartite model so that, in mammals, the dorsal pallium now includes only the six-layered neocortex, which is surrounded by a double ring (Fig. 2b). The inner ring is the mesocortical one, which includes laterally the lateral pallium (claustroinsular region plus other areas, as explained above) and continues medially with the cingular/retrosplenial cortices. The outer ring is the allocortical one, represented laterally by the ventral pallium (excluding the amygdala) and medially by the medial pallium. In the double-ring model, the entorhinal cortex and pre/parasubiculum are considered a different pallial sector of the allocortical ring at caudal levels (called "schizocortex" because of its split architecture), interposed between ventral and medial pallium (Fig. 2b). In the double-ring model, the pallial amygdala is excluded from the ring-like cortical pallium, based on its putative different origin [Puelles et al., 2019a; García-Calero et al., 2020]. This implies recognizing the existence of a distinct pallial amygdala division. In contrast to the double-ring pallial model [Puelles et al., 2019a], the structural model considers the pallial amygdala as a separate part inside the allocortical ring (Fig. 2c) [see also Fig. 4a in García-Cabezas et al., 2019].

The double-ring and structural models are claimed to be better for explaining architecture and molecular features of the pallium throughout ontogenesis, and to be more powerful for predicting the development and evolution of each pallial sector [García-Cabezas et al., 2019; Puelles et al., 2019a]. When the double-ring model is represented in plane using correct topological coordinates, including the roof plate and other known sources of morphogenetic signals, it becomes easier to understand the topological position and neighbour relations of different pallial divisions, and to predict possible sources of yet unknown signals (for example, the amygdala is proposed as a possible source of signals that contribute to shape the schizocortex [Puelles et al., 2019a]). According to the structural model, this also helps to predict different patterns of myelinization, strength of cortical connections, plasticity and susceptibility to disease: compared to the eulaminar-type cortex, the dysgranular and agranulartype cortices show lower myelinization and strength of cortical connections, higher plasticity and more susceptibility to neurodegeneration and malfunction in psychiatric disorders [García-Cabezas et al., 2019].

While recognizing the high impact of these interesting models, we see aspects that require attention. For simplicity, we focus on the double-ring pallial model to highlight aspects to consider (some of them also apply to the structural model). First, the model does not explain differences in the expression of critical genes such as Lef1 between medial and lateral entorhinal cortices. According to our interpretation, the interesting results on enhancers driving gene expression in different cortical domains and associated fate mapping [Pattabiraman et al., 2014] support continuity of orbitofrontal cortex, claustroinsular region, and perirhinal cortex with the lateral entorhinal cortex (for example, enhancer 671), but not with the medial entorhinal cortex, whose gene expression is driven by enhancers also active in the hippocampal formation, plus pre- and parasubiculum (such as enhancer 1050). Thus, according to our interpretation, the enhancer-related results would agree with the proposal of the hexapartite model. Second, the model forces into the ring system medial and lateral areas (on both sides of the dorsal pallium) that differ in many respects, such as embryonic origin and enhancer activity [Pattabiraman et al., 2014], gene expression profile (for example, only medial regions express Lef1 [Abellán et al., 2014]) and structure (only the lateral regions include a distinct nuclear deep stratum, represented by the claustrum at some levels). Third, the model is highly corticocentric, leaving the amygdala outside the ring system. While recognizing that the pallial amygdala is a different unit, in our opinion, the model does not explain satisfactorily the neighbour relationships between the ventral endopiriform/piriform region and the pallial amygdala, and the molecular continuum of both sectors at the ventricular level (e.g., with Dbx1 and Sfr2). As noted above, this is solved in the structural model by including the amygdala as a separate part of the allocortical ring. Fifth, the planar representation of the pallial model and its predictive potential would benefit if some of the deformations seen in the tissue from very early (neural plate) stages were considered. This would facilitate better comprehension of areas under the influence of different, sometimes synergic and other times antagonic, morphogenetic signals and their variation during development. Sixth, the model is highly mammalian-centric, giving excessive importance to the dorsal pallium, which is very small in sauropsids (in the best of the cases, but see critical review by Striedter and Northcutt [2020]), and perhaps it is absent in anamniotes. Most of the pallium in 
sauropsids and anamniotes seems to be formed by parts of the mammalian mesocortical and allocortical rings, plus the pallial amygdala, and there is no evidence for a ring-like system. In this situation, the double-ring pallial model would only be representative of mammalian pallial organization, but not of the pallium of most vertebrates.

\section{Transcriptome Data, Pallial Models and Homologies}

According to results from a whole-cell transcriptome, the only pallial sector showing significant similarity in the adult transcriptome profile between the chicken and mouse is the medial pallium (hippocampal formation) [Belgard et al., 2013], which agrees with previous proposals of homology [as discussed by Butler, 1994; Striedter, 1997; Reiner et al., 2004; Medina et al., 2017a; Desfilis et al., 2018]. However, in contrast to the proposals of homology between sauropsid DVR and pallial amygdala based on their similar embryonic origin and partially similar gene expression during development, whole-cell transcriptome analysis of the DVR region in adult chickens has shown a highly divergent gene expression pattern when compared to the mouse pallial amygdala [Belgard et al., 2013; Belgard and Montiel, 2013]. This study also showed high differences in the transcriptome profile between chicken DVR and mouse neocortex, although partial similarity (weak, but significant) was found when comparing thalamorecipient nuclei of the chicken DVR (in particular, the entopallium) and the thalamorecipient layer 4 of the neocortex, suggesting convergence in some patterns [Belgard et al., 2013; see also a study by Briscoe et al., 2018, focused on the mesopallium]. It has also become evident that in the adult zebra finch (a songbird) there is a high similarity in transcriptome profile between ventral and dorsal pallia [Gedman et al., 2021], which agrees with previous results on the expression of similar groups of genes in thalamorecipient areas of the DVR and Wulst of chicken [Dugas-Ford et al., 2012]. Gedman et al. [2021] claimed that their results likely are a common feature of all avian brains and support a continuity of pallial domains from dorsal to ventral [Chen et al., 2013; Jarvis et al., 2013; Gedman et al., 2021]. However, the dorsal and ventral domains showing "molecular continuity" are not developmental radial units (fate mapping studies do not support such continuity [Cobos et al., 2001; GarcíaMoreno et al., 2018]). The gene expression similarities include motifs related to late developmental events, such as dendritogenesis and neural connectivity [Gedman et al., 2021], but not to early patterning and progenitor specification.

Gene regulatory networks involved in development are hierarchically organized, and it appears that genes at top levels of each network (such as those involved in patterning and specification of distinct progenitor fields that produce different body parts) are subjected to high constraints against variation and, consequently, are more conserved in evolution [Peter and Davidson, 2011]. The level of constraint diminishes gradually from top to bottom in the network. Thus, variation at the level of effector (activity-related) genes is subjected to lower constraint and can occur more often in evolution [Peter and Davidson, 2011]. It is likely that topological similarities at the level of gene expression profile between dorsal and ventral parts of the avian pallium represent a case of convergence in genes of lower levels of regulatory networks. There are many cases of convergence in genetic toolkits related to particular functions, such as those involved in viviparity (live birth), which has evolved more than 150 times in divergent evolutionary lineages of vertebrates [Whittington et al., 2015]. The study of cases of convergence in the pallium is highly interesting for identifying minimal molecular toolkits needed to achieve particular functions. These convergent genetic toolkits may also be responsible for the similarities (analogies) found at the level of connections in the pallium of different vertebrates [for example, Stacho et al., 2020] and may explain the convergence seen at circuit level.

One interesting observation that emerges from transcriptome studies in the pallium is the identification of genes that appear to play essential roles in particular divisions: for example, Lhx9 and Etv1 (ER81) in the arcopallium/posterior DVR [Tosches et al., 2018; Gedman et al., 2021], and Satb 2 and Gng4 in the mesopallium and corresponding divisions of non-avian reptiles [Briscoe et al., 2018; Gedman et al., 2021]. These can be useful to identify similar cell populations in derivatives of homologous pallial divisions of different vertebrates. For example, the high similarity in gene expression profile between dorsal and ventral mesopallium [Briscoe et al., 2018; Gedman et al., 2021] resembles that found between the insular claustrum and the adjacent dorsal endopiriform nucleus of mammals (in both cases they express Satb2, Gng4 and Nr4a2/Nurr1 [Gedman et al., 2021; for the mouse see Puelles, 2014, and Allen Developing Mouse Brain Atlas]. Puelles [2014] suggested a dorsoventral migration of $\mathrm{Nr} 4 \mathrm{a} 2$ cells that, if confirmed, may explain the similarities found between the dorsal endopiriform nucleus and the insular claustrum. However, Nr4a2 cells can also be pro- 
duced in other pallial divisions, including the ventral pallium [Moreau et al., 2021].

The transcriptome results can also be useful to help delineating new units/subunits or to improve understanding of others. For example, using single-cell RNAseq in the developing mouse cortex, Moreau et al. [2021] found a graded expression of patterning genes from ventral to dorsal, leading to a partition proposal that apparently agrees with that of the hexapartite model. This opens the venue for doing similar studies in the developing pallium of other amniotes in order to compare these sectors across species.

Using transcriptome analysis in the avian pallium, Jarvis' team [Jarvis et al., 2013; Gedman et al., 2021] claimed that the so-called densocellular hyperpallium of previous studies in birds is part of the mesopallium and, accordingly, they called it dorsal mesopallium. However, as discussed previously [Medina et al., 2019], there has often been a confusion in the literature in the identification of the densocellular hyperpallium at rostral levels: in some studies, it is clear that, rostrally, some authors use the densocellular hyperpallium to refer to a division lateral to the medial vallecula and, therefore, not part of the hyperpallium or Wulst. At these rostral levels, this division resembles the dorsolateral pallium of the hexapartite pallial model [Medina et al., 2019]. Clarifying this issue is important for homology considerations. In addition, transcriptome studies in the avian pallium helped to identify the intercalated nidopallium (in the ventral pallium), which includes the sensory nuclei of the DVR, as a separate entity [Chen et al., 2013; Jarvis et al., 2013; Gedman et al., 2021]. Fate mapping analysis indicates that cells that populate these sensory nuclei of the DVR constitute a developmental radial unit, as they originate in a ventricular sector of the caudal nidopallium and distribute radially from caudomedial (where the auditory field L locates) to rostrolateral levels (where the somatosensory basorostral nucleus is found) [Striedter et al., 1998] (we represented this distinct radial unit as a subdivision of the ventral pallium in Fig. 2a, b). These developmental units, subunits or cell populations of major divisions should also be taken into consideration in homology discussions.

The results from whole-cell transcriptome analysis highlight that we should be extremely cautious with assuming that homologous embryonic divisions produce homologous adult structures because new subunits and/ or cell subpopulations might have been produced in different species [discussed by Puelles and Medina, 2002; Striedter, 2005; Medina, 2007; Aboitiz and Montiel, 2012; Nieuwenhuys and Puelles, 2016; Striedter and Northcutt,
2020]. Moreover, some of the pre-existing cell populations may have acquired new features, leading some authors to raise additional questions on the degree of homology of the modified cells [as discussed by Striedter and Northcutt, 2020]. Here we should remember that homology is independent of modifications in form and function [Puelles and Medina, 2002], but in cases of great divergence, like the pallium, it is not easy to distinguish between homology and analogy.

In front of these discussions, is it useful to have a model that is based on embryonic FMUs and related radial units? The answer is yes, it is extremely relevant because the embryonic origin, by way of the set of regulatory genes expressed in each specific division of the morphospace at early stages [Peter and Davidson, 2011], conditions what is and is not possible for the cells produced there, such as their neurotransmitter/neuropeptide content and their expression of membrane proteins related to cell aggregation, migration, axonal pathfinding and synaptogenesis [reviewed by Medina et al., 2017b]. Of course, this does not mean that there is no space for plasticity and modification due to external factors, or for divergence of the same unit between species (due to interspecies variation in the gene regulatory networks involved in the development of that unit [Peter and Davidson, 2011]), but some features are determined early. In other words, some events that occur at each FMU/radial unit during embryonic development permanently organize some aspects of the mature unit. Moreover, different studies have indicated that transcription factors expressed during development are the most robust discriminators of neuronal types [reviewed by Ruiz-Ortiz and Tollkuhn, 2021; see also Arendt et al., 2016]. This means that neurons produced in the same embryonic unit share some basic features and may be susceptible or resistant to similar challenges, which is relevant not only for understanding general brain organizing principles shared by different species, but also for understanding susceptibility to disease. For the same reason, it is predicted that non-homologous cells (such as pallial cells derived from different embryonic fields) would likely show different behaviour in front of neurodevelopmental and environmental challenges, even if there is convergence of some adult features. Taking into account all of these considerations, it would be relevant to do more studies throughout ontogenesis and including more species to fill the gap between embryonic development and adult structure. Since most radial divisions include a mixture of different cell types, these studies should include single-cell transcriptomic approaches, which allow better discrimination of the degree 
of conservation, divergence or convergence of the different neuron populations found in each particular radial histogenetic field. For the moment, the single-cell transcriptomic approach has been used to compare different pallial sectors of adult turtles and mice [Tosches et al., 2018] and specific song-related pallial areas of the songbird DVR with different pallial areas of the mouse [Colquitt et al., 2021]. These studies have shown that when separating excitatory (glutamatergic) neurons from inhibitory (GABAergic) neurons and from glial cells, it turns out that the transcriptome profile of specific neurons reveals significant similarities between DVR and pallial amygdala, rather than between DVR and neocortex [Tosches et al., 2018; Colquitt et al., 2021]. For example, significant similarities in the transcriptome profile were found between excitatory neurons of the reptilian anterior DVR and those of the lateral nucleus of the mammalian pallial amygdala, and between excitatory neurons of the reptilian posterior DVR with similar cell populations of other parts of the mammalian pallial amygdala [Tosches et al., 2018]. In addition, significant similarities were found regarding transcription factor expression in excitatory neurons of the high vocal centre and the nucleus robustus arcopallialis in the songbird DVR and the mammalian ventral pallium (including the pallial amygdala at caudal levels), but not with those of the dorsal pallium (neocortex) [Colquitt et al., 2021]. In contrast, when examining only effector genes (encoding non-transcription factors) of excitatory neurons, a significant similarity was found between DVR and neocortex (without specificity for specific cortical layers or areas), but not with the mammalian ventral pallium [Colquitt et al., 2021]. The authors interpret this finding as evidence of convergence in particular function-related traits [Colquitt et al., 2021; see also Pfenning et al., 2014]. Remarkably, convergent patterns in expression of effector genes in different pallial sectors seem to be produced by different networks of transcription factors. These results argue against the indiscriminate use of "cell-type homology" for comparing pallial areas [as done, for example, by Briscoe and Ragsdale, 2018] without considering other important aspects, such as the embryonic field from which the cells derive.

\section{Conclusions: Power and Limitations of Models for Understanding Pallial Evolution}

The pallium is the largest and most divergent part of the telencephalon in amniotes, and comparison of its subdivisions across species has been extremely difficult and highly controversial. Even within mammals, the use of few "species models" for brain research has made it difficult to extract general principles that can be extrapolated to the human brain, raising the need of expanding the scope, helping to identify general principles as well as to ask more focused and insightful questions. The emergence of the evolutionary developmental biology discipline, applied to the nervous system, has changed our way of understanding the brain by identifying genetic toolkits responsible of regionalization and specification of basic units, as well as variations responsible of evolution (usually at the level of cis-regulatory elements [enhancers] of developmental regulatory genes [Carroll et al., 2001; Carroll, 2005; Peter and Davidson, 2011]). With this in mind, comparative embryonic genoarchitecture studies have greatly contributed to propose models of pallial fundamental divisions, which are being extremely useful to compare across species. Luis Puelles was a pioneer on these studies, and with the help of his team has provided insightful proposals - still evolving to incorporate and adapt to new results - that have shaped the way several generations of neuroscientists (including us) are understanding the brain and addressing research. Although the models they proposed (tetrapartite model and, more recently, double-ring model) were mostly based on the embryonic brain of amniotes, it has been successfully applied to anamniotes by excellent contributions by Agustín González and colleagues, Mario Wullimann and colleagues, and Isabel Rodríguez-Moldes and colleagues.

While recognizing the power of these models for understanding brain architecture (at cellular, molecular and circuit levels), development and evolution, we would also like to note their limitations, highlighting the following aspects:

1. Models are not fixed frameworks, and we should hamper to use them dogmatically. They should be based on nature (i.e., brain data) and not the other way around. Thus, models need to be continuously revised to adapt for new results. In this regard, it is important to remember that we, humans, have a tendency to pay attention to data that adjust well to our previous conceptions, but this is very dangerous in research and can prevent progress. Considering this, we need to also pay special attention to those results that do not fit well in our scheme, because these might provide important cues to advance

2. Models can evolve, as the brain does. This means, brains can change in evolution, not only in the transition from protochordates to vertebrates, but also within vertebrates, and brain-based models should also re- 
flect this variation. New divisions can arise from parcellation of previous fields, and this might have happened in the evolution of the dorsal pallium (perhaps by parcellation of a previous medial pallial sector). Moreover, we should be open to the existence of divergence and convergence not only at the level of pre-existing fields, but also at the level of appearance of new fields only in some lineages

3. When comparing the same field in different lineages, we should avoid the temptation of going too far in identification of exactly the same nuclei or areas in every single species. Regarding the discussion in the previous sections, perhaps it does not make sense to try to find the claustrum or the insular cortex, or even the neocortex in all amniotes and in anamniotes. For example, it is clear that a structure such as the neocortex is unique to mammals, in the same way that a structure such as the Wulst is unique to birds, even if both appear to derive from a dorsal pallial division present in their most recent common ancestor. The same applies to the mammalian pallial amygdala versus the sauropsid DVR. Still, the fact of a common embryonic origin can reveal aspects or principles of their organization that can be relevant for understanding not only the degree of conservation or divergence in their evolution, but also their function and susceptibility to disease.

\section{Conflict of Interest Statement}

The authors have no conflicts of interest to declare.

\section{Funding Sources}

This work was funded by a grant from the Spanish Ministerio de Ciencia e Innovación (grant No. PID2019-108725RB-100).

\section{Author Contributions}

All authors contributed substantially to the conception of the work in relation to pallial genoarchitecture and divisions. L.M. prepared the first draft of the manuscript. E.D. and A.A. discussed and contributed to improve the manuscript. All approved the final version and agreed with the data presented.

\section{References}

Abellán A, Desfilis E, Medina L. Combinatorial expression of Lef1, Lhx2, Lhx5, Lhx9, Lmo3, Lmo4, and Prox1 helps to identify comparable subdivisions in the developing hippocampal formation of mouse and chicken. Front Neuroanat. 2014 Jul;8:59.

Abellán A, Legaz I, Vernier B, Rétaux S, Medina L. Olfactory and amygdalar structures of the chicken ventral pallium based on the combinatorial expression patterns of LIM and other developmental regulatory genes. J Comp Neurol. 2009 Sep;516(3):166-86.

Abellán A, Medina L. Subdivisions and derivatives of the chicken subpallium based on expression of LIM and other regulatory genes and markers of neuron subpopulations during development. J Comp Neurol. 2009 Aug; 515(4):465-501.

Abellán A, Vernier B, Rétaux S, Medina L. Similarities and differences in the forebrain expression of Lhx1 and Lhx5 between chicken and mouse: insights for understanding telencephalic development and evolution. J Comp Neurol. 2010 Sep;518(17):3512-28.

Aboitiz F, Montiel JF. From tetrapods to primates: conserved developmental mechanisms in diverging ecological adaptations. Prog Brain Res. 2012;195:3-24.

Affaticati P, Yamamoto K, Rizzi B, Bureau C, Peyriéras $\mathrm{N}$, Pasqualini $\mathrm{C}$, et al. Identification of the optic recess region as a morphogenetic en- tity in the zebrafish forebrain. Sci Rep. 2015 Mar;5(1):8738.

Albuixech-Crespo B, López-Blanch L, Burguera D, Maeso I, Sánchez-Arrones L, Moreno-Bravo JA, et al. Molecular regionalization of the developing amphioxus neural tube challenges major partitions of the vertebrate brain. PLoS Biol. 2017 Apr;15(4):e2001573.

Allen Institute for Brain Science. Allen Developing Mouse Brain Atlas [Internet]. 2013. Available from: http://developingmouse.brainmap.org.

Alzu'bi A, Lindsay SJ, Harkin LF, McIntyre J, Lisgo SN, Clowry GJ. The Transcription Factors COUP-TFI and COUP-TFII have Distinct Roles in Arealisation and GABAergic Interneuron Specification in the Early Human Fetal Telencephalon. Cereb Cortex. 2017 Oct; 27(10):4971-87.

Arendt D, Musser JM, Baker CV, Bergman A, Cepko C, Erwin DH, et al. The origin and evolution of cell types. Nat Rev Genet. 2016 Dec;17(12):744-57.

Bachy I, Berthon J, Rétaux S. Defining pallial and subpallial divisions in the developing Xenopus forebrain. Mech Dev. 2002a Sep;117(12):163-72.

Bachy I, Failli V, Rétaux S. A LIM-homeodomain code for development and evolution of forebrain connectivity. Neuroreport. 2002b Feb; 13(2):A23-7.
Bachy I, Vernier P, Retaux S. The LIM-homeodomain gene family in the developing Xenopus brain: conservation and divergences with the mouse related to the evolution of the forebrain. J Neurosci. 2001 Oct;21(19):7620-9.

Belgard TG, Montiel JF, Wang WZ, García-Moreno F, Margulies EH, Ponting CP, et al. Adult pallium transcriptomes surprise in not reflecting predicted homologies across diverse chicken and mouse pallial sectors. Proc Natl Acad Sci USA. 2013 Aug;110(32):13150-5.

Belgard TG, Montiel JF. Things change: how comparative transcriptomics suggest the pallium has evolved at multiple levels of organization. Brain Behav Evol. 2013;82(3):150-2.

Bergquist H. Zur Morphologie des Zwischenhirns bei niederen Wirbeltieren. Acta Zool (Stockh). 1932;34:155-90.

Bergquist $H$, Källén B. On the development of neuromeres to migration areas in the vertebrate cerebral tube. Acta Anat (Basel). 1953; 18(1):65-73.

Bergquist H, Källén B. Notes on the early histogenesis and morphogenesis of the central nervous system in vertebrates. J Comp Neurol. 1954 Jun;100(3):627-59.

Bielle F, Griveau A, Narboux-Nême N, Vigneau S, Sigrist M, Arber S, et al. Multiple origins of Cajal-Retzius cells at the borders of the developing pallium. Nat Neurosci. 2005 Aug;8(8): 1002-12. 
Bishop KM, Garel S, Nakagawa Y, Rubenstein JL, O'Leary DD. Emx1 and Emx2 cooperate to regulate cortical size, lamination, neuronal differentiation, development of cortical efferents, and thalamocortical pathfinding. J Comp Neurol. 2003 Mar;457(4):345-60.

Bishop KM, Rubenstein JL, O’Leary DD. Distinct actions of Emx1, Emx2, and Pax6 in regulating the specification of areas in the developing neocortex. J Neurosci. 2002 Sep;22(17):762738.

Bolker JA. Selection of Models: Evolution and the Choice of Species for Translational Research. Brain Behav Evol. 2019;93(2-3):82-91.

Briscoe SD, Albertin CB, Rowell JJ, Ragsdale CW. Neocortical Association Cell Types in the Forebrain of Birds and Alligators. Curr Biol. 2018 Mar;28(5):686-696.e6.

Briscoe SD, Ragsdale CW. Homology, neocortex, and the evolution of developmental mechanisms. Science. 2018 Oct;362(6411):190-3.

Brox A, Puelles L, Ferreiro B, Medina L. Expression of the genes GAD67 and Distal-less-4 in the forebrain of Xenopus laevis confirms a common pattern in tetrapods. J Comp Neurol. 2003 Jun;461(3):370-93.

Brox A, Puelles L, Ferreiro B, Medina L. Expression of the genes Emx1, Tbr1, and Eomes (Tbr2) in the telencephalon of Xenopus laevis confirms the existence of a ventral pallial division in all tetrapods. J Comp Neurol. 2004 Jul;474(4):562-77.

Bruce LL, Neary TJ. The limbic system of tetrapods: a comparative analysis of cortical and amygdalar populations. Brain Behav Evol. 1995;46(4-5):224-34.

Bulchand S, Grove EA, Porter FD, Tole S. LIMhomeodomain gene Lhx2 regulates the formation of the cortical hem. Mech Dev. 2001 Feb;100(2):165-75.

Butler AB. The evolution of the dorsal pallium in the telencephalon of amniotes: cladistic analysis and a new hypothesis. Brain Res Brain Res Rev. 1994 Jan;19(1):66-101.

Carroll SB. Evolution at two levels: on genes and form. PLoS Biol. 2005 Jul;3(7):e245.

Carroll SB, Grenier JK, Weatherbee SD. From DNA to Diversity. Molecular Genetics and the Evolution of Animal Design. London (UK): Blackwell Science; 2001.

Chen CC, Winkler CM, Pfenning AR, Jarvis ED. Molecular profiling of the developing avian telencephalon: regional timing and brain subdivision continuities. J Comp Neurol. 2013 Nov;521(16):3666-701.

Cobos I, Shimamura K, Rubenstein JL, Martínez S, Puelles L. Fate map of the avian anterior forebrain at the four-somite stage, based on the analysis of quail-chick chimeras. Dev Biol. 2001 Nov;239(1):46-67.

Colquitt BM, Merullo DP, Konopka G, Roberts TF, Brainard MS. Cellular transcriptomics reveals evolutionary identities of songbird vocal circuits. Science. 2021 Feb;371(6530):eabd9704. https://doi.org/10.1126/science.abd9704.

Desfilis E, Abellán A, Sentandreu V, Medina L. Expression of regulatory genes in the embry- onic brain of a lizard and implications for understanding pallial organization and evolution. J Comp Neurol. 2018 Jan;526(1):166202.

Di Bonito M, Studer M, Puelles L. Nuclear derivatives and axonal projections originating from rhombomere 4 in the mouse hindbrain. Brain Struct Funct. 2017 Nov;222(8):350942.

Domínguez L, González A, Moreno N. Sonic hedgehog expression during Xenopus laevis forebrain development. Brain Res. 2010 Aug; 1347:19-32.

Domínguez L, Morona R, González A, Moreno N. Characterization of the hypothalamus of Xenopus laevis during development. I. The alar regions. J Comp Neurol. 2013 Mar;521(4): 725-59.

Dugas-Ford J, Rowell JJ, Ragsdale CW. Cell-type homologies and the origins of the neocortex. Proc Natl Acad Sci USA. 2012 Oct;109(42): 16974-9.

Eaton JL, Holmqvist B, Glasgow E. Ontogeny of vasotocin-expressing cells in zebrafish: selective requirement for the transcriptional regulators orthopedia and single-minded 1 in the preoptic area. Dev Dyn. 2008 Apr;237(4):9951005.

Ferran JL, de Oliveira ED, Merchán P, Sandoval JE, Sánchez-Arrones L, Martínez-De-LaTorre M, et al. Genoarchitectonic profile of developing nuclear groups in the chicken pretectum. J Comp Neurol. 2009 Dec;517(4):40551.

Ferran JL, Puelles L, Rubenstein JL. Molecular codes defining rostrocaudal domains in the embryonic mouse hypothalamus. Front Neuroanat. 2015 Apr;9:46.

Ferran JL, Sánchez-Arrones L, Sandoval JE, Puelles L. A model of early molecular regionalization in the chicken embryonic pretectum. J Comp Neurol. 2007 Dec;505(4):379-403.

Galceran J, Miyashita-Lin EM, Devaney E, Rubenstein JL, Grosschedl R. Hippocampus development and generation of dentate gyrus granule cells is regulated by LEF1. Development. $2000 \mathrm{Feb} ; 127(3): 469-82$.

Ganz J, Kroehne V, Freudenreich D, Machate A, Geffarth M, Braasch I, et al. Subdivisions of the adult zebrafish pallium based on molecular marker analysis. F1000 Res. 2014 Dec; 3:308.

García-Cabezas MÁ, Zikopoulos B, Barbas H. The Structural Model: a theory linking connections, plasticity, pathology, development and evolution of the cerebral cortex. Brain Struct Funct. 2019 Apr;224(3):985-1008.

García-Calero E, Martínez-de-la-Torre M, Puelles L. A radial histogenetic model of the mouse pallial amygdala. Brain Struct Funct. 2020 Sep;225(7):1921-56.

García-Calero E, Puelles L. Development of the mouse anterior amygdalar radial unit marked by Lhx9-expression. Brain Struct Funct. 2021 Mar;226(2):575-600.

García-López M, Abellán A, Legaz I, Rubenstein JL, Puelles L, Medina L. Histogenetic com- partments of the mouse centromedial and extended amygdala based on gene expression patterns during development. J Comp Neurol. 2008 Jan;506(1):46-74.

García-López R, Vieira C, Echevarría D, Martínez $S$. Fate map of the diencephalon and the zona limitans at the 10-somites stage in chick embryos. Dev Biol. 2004 Apr;268(2):514-30.

García-Moreno F, Anderton E, Jankowska M, Begbie J, Encinas JM, Irimia M, et al. Absence of Tangentially Migrating Glutamatergic Neurons in the Developing Avian Brain. Cell Rep. 2018 Jan;22(1):96-109.

Gedman G, Haase B, Durieux G, Biegler MT, Fedrigo O, Jarvis ED. As above, so below: whole transcriptome profiling demonstrates strong molecular similarities between avian dorsal and ventral pallial subdivisions. J Comp Neurol. 2021 Aug;529(12):3222-46.

González A, López JM, Marín O. Expression pattern of the homeobox protein NKX2-1 in the developing Xenopus forebrain. Gene Expr Patterns. 2002 Oct;1(3-4):181-5.

González A, López JM, Sánchez-Camacho C, Marín O. Regional expression of the homeobox gene NKX2-1 defines pallidal and interneuronal populations in the basal ganglia of amphibians. Neuroscience. 2002;114(3):56775.

González A, Morona R, Moreno N, Bandín S, López JM. Identification of striatal and pallidal regions in the subpallium of anamniotes. Brain Behav Evol. 2014;83(2):93-103.

González A, Northcutt RG. An immunohistochemical approach to lungfish telencephalic organization. Brain Behav Evol. 2009;74(1): 43-55.

Gupta S, Maurya R, Saxena M, Sen J. Defining structural homology between the mammalian and avian hippocampus through conserved gene expression patterns observed in the chick embryo. Dev Biol. 2012 Jun;366(2):12541.

Hale ME. Mapping circuits beyond the models: integrating connectomics and comparative neuroscience. Neuron. 2014 Sep;83(6):12568.

Hale ME. Toward diversification of species models in neuroscience. Brain Behav Evol. 2019; 93(2-3):166-8.

Herrick CJ. The morphology of the forebrain in amphibian and reptilia. J Comp Neurol. 1910;20:413-547.

Hevner RF, Shi L, Justice N, Hsueh Y, Sheng M, Smiga S, et al. Tbr1 regulates differentiation of the preplate and layer 6. Neuron. 2001 Feb;29(2):353-66.

Holmgren N. Points of view concerning forebrain morphology in lower vertebrates. J Comp Neurol. 1922;34(5):459-91.

Holmgren N. Points of view concerning forebrain morphology in higher vertebrates. Acta Zool. 1925;6(3):413-77.

Hoops D, Desfilis E, Ullmann JF, Janke AL, StaitGardner T, Devenyi GA, et al. A 3D MRIbased atlas of a lizard brain. J Comp Neurol. 2018 Nov;526(16):2511-47. 
Jarvis ED, Güntürkün O, Bruce L, Csillag A, Karten H, Kuenzel W, et al.; Avian Brain Nomenclature Consortium. Avian brains and a new understanding of vertebrate brain evolution. Nat Rev Neurosci. 2005 Feb;6(2):151-9.

Jarvis ED, Yu J, Rivas MV, Horita H, Feenders G, Whitney $\mathrm{O}$, et al. Global view of the functional molecular organization of the avian cerebrum: mirror images and functional columns. J Comp Neurol. 2013 Nov;521(16):3614-65.

Källén B. Embryological studies on the nuclei and their homologization in the vertebrate forebrain. Kgl Fysiogr Sällsk Lund Handl N F. 1951;61:3-43.

Källén B. On the significance of neuromeres and similar structures in vertebrate embryos. J Embryol Exp Morphol. 1953;1:387-92.

Karten HJ. Evolutionary developmental biology meets the brain: the origins of mammalian cortex. Proc Natl Acad Sci USA. 1997 Apr; 94(7):2800-4.

Kitagawa D, Watanabe T, Saito K, Asaka S, Sasado T, Morinaga C, et al. Genetic dissection of the formation of the forebrain in Medaka, Oryzias latipes. Mech Dev. 2004 Jul;121(7-8):673-85.

Kuhlenbeck H. The central nervous system of vertebrates. Basel: Karger; 1973. Vol. 3, Part II: Overall morphological pattern.

Lavado A, Lagutin OV, Chow LM, Baker SJ, Oliver G. Prox 1 is required for granule cell maturation and intermediate progenitor maintenance during brain neurogenesis. PLoS Biol. 2010 Aug;8(8):e1000460.

Lindsay S, Sarma S, Martínez-de-la-Torre M, Kerwin J, Scott M, Luis Ferran J, et al. Anatomical and gene expression mapping of the ventral pallium in a three-dimensional model of developing human brain. Neuroscience. 2005;136(3):625-32.

Marín F, Puelles L. Morphological fate of rhombomeres in quail/chick chimeras: a segmental analysis of hindbrain nuclei. Eur J Neurosci. 1995 Aug;7(8):1714-38.

Martínez-García F, Martínez-Marcos A, Lanuza E. The pallial amygdala of amniote vertebrates: evolution of the concept, evolution of the structure. Brain Res Bull. 2002 Feb-Mar; 57(3-4):463-9.

Martínez-García F, Novejarque A, Lanuza E. Evolution of the amygdala in vertebrates. In: Kass $\mathrm{JH}$, editor. Evolution of Nervous Systems. A Comprehensive Reference. Oxford: ElsevierAcademic Press; 2007. Vol. 2, p. 255-334.

Medina L. Field homologies. In: Kaas JH, Striedter GF, Rubenstein JLR, editors. Evolution of nervous systems: a comprenhensive reference. Amsterdam: Academic Press-Elsevier; 2007. Vol. 1: Theories, development, invertebrates, p. 73-87. https://doi.org/10.1016/B012-370878-8/00097-5.

Medina L, Abellán A. Development and evolution of the pallium. Semin Cell Dev Biol. 2009 Aug;20(6):698-711.

Medina L, Abellán A, Desfilis E. Contribution of Genoarchitecture to Understanding Hippocampal Evolution and Development. Brain Behav Evol. 2017a;90(1):25-40.
Medina L, Abellán A, Desfilis E. Evolution of pallial areas and networks involved in sociality: comparison between mammals and sauropsids. Front Physiol. 2019 Jul;10:894.

Medina L, Abellán A, Vicario A, Castro-Robles B, Desfilis E. The amygdala. In: Kaas JH, editor. Evolution of nervous systems. 2nd ed. Oxford: Elsevier; 2017b. Vol. 1, p. 427-78.

Medina L, Bupesh M, Abellán A. Contribution of genoarchitecture to understanding forebrain evolution and development, with particular emphasis on the amygdala. Brain Behav Evol. 2011;78(3):216-36.

Medina L, Legaz I, González G, De Castro F, Rubenstein JL, Puelles L. Expression of Dbx1, Neurogenin 2, Semaphorin 5A, Cadherin 8, and Emxl distinguish ventral and lateral pallial histogenetic divisions in the developing mouse claustroamygdaloid complex. J Comp Neurol. 2004 Jul;474(4):504-23.

Morales L, Castro-Robles B, Abellán A, Desfilis E, Medina L. A novel telencephalon-opto-hypothalamic morphogenetic domain coexpressing Foxg1 and Otp produces most of the glutamatergic neurons of the medial extended amygdala. J Comp Neurol. 2021 Jul;529(10): 2418-49.

Moreau MX, Saillour Y, Cwetsch AW, Pierani A, Causeret F. Single-cell transcriptomics of the early developing mouse cerebral cortex disentangle the spatial and temporal components of neuronal fate acquisition. Development. 2021 Jul;148(14):dev197962. https://doi. org/10.1242/dev.197962.

Moreno N, Bachy I, Rétaux S, González A. LIMhomeodomain genes as developmental and adult genetic markers of Xenopus forebrain functional subdivisions. J Comp Neurol. 2004 Apr;472(1):52-72.

Moreno N, Domínguez L, Morona R, González A. Subdivisions of the turtle Pseudemys scripta hypothalamus based on the expression of regulatory genes and neuronal markers. J Comp Neurol. 2012 Feb;520(3):453-78.

Moreno N, Domínguez L, Rétaux S, González A. Isletl as a marker of subdivisions and cell types in the developing forebrain of Xenopus. Neuroscience. 2008a Jul;154(4):1423-39.

Moreno N, González A. The common organization of the amygdaloid complex in tetrapods: new concepts based on developmental, hodological and neurochemical data in anuran amphibians. Prog Neurobiol. 2006 Feb; 78(2):61-90.

Moreno N, Morona R, López JM, González A. Subdivisions of the turtle Pseudemys scripta subpallium based on the expression of regulatory genes and neuronal markers. J Comp Neurol. 2010 Dec;518(24):4877-902.

Moreno N, Rétaux S, González A. Spatio-temporal expression of Pax6 in Xenopus forebrain. Brain Res. 2008b Nov;1239:92-9.

Moreno-Bravo JA, Martinez-Lopez JE, Madrigal MP, Kim M, Mastick GS, Lopez-Bendito G, Martinez S, Puelles E. 2016. Developmental guidance of the retroflex tract at its bending point involves Robo1-Slit2-mediated floor plate repulsion. Brain Struct Funct. 2016; 221(1):665-78.

Morona R, Ferran JL, Puelles L, González A. Embryonic genoarchitecture of the pretectum in Xenopus laevis: a conserved pattern in tetrapods. J Comp Neurol. 2011 Apr;519(6):102450.

Mueller T, Vernier P, Wullimann MF. A phylotypic stage in vertebrate brain development: GABA cell patterns in zebrafish compared with mouse. J Comp Neurol. 2006 Feb; 494(4):620-34.

Mueller T, Wullimann MF. An evolutionary interpretation of teleostean forebrain anatomy. Brain Behav Evol. 2009;74(1):30-42.

Mueller T, Wullimann MF. Expression domains of neuroD (nrd) in the early postembryonic zebrafish brain. Brain Res Bull. 2002 FebMar;57(3-4):377-9.

Mueller T, Wullimann MF, Guo S. Early teleostean basal ganglia development visualized by zebrafish Dlx2a, Lhx6, Lhx7, Tbr2 (eomesa), and GAD67 gene expression. J Comp Neurol. 2008 Mar;507(2):1245-57.

Murakami Y, Ogasawara M, Sugahara F, Hirano S, Satoh N, Kuratani S. Identification and expression of the lamprey Pax6 gene: evolutionary origin of the segmented brain of vertebrates. Development. 2001 Sep;128(18):352131.

Murakami Y, Uchida K, Rijli FM, Kuratani S. Evolution of the brain developmental plan: insights from agnathans. Dev Biol. 2005 Apr;280(2):249-59.

Murillo B, Ruiz-Reig N, Herrera M, Fairén A, Herrera E. Zic2 Controls the Migration of Specific Neuronal Populations in the Developing Forebrain. J Neurosci. 2015 Aug; 35(32):11266-80.

Muzio L, Di Benedetto B, Stoykova A, Boncinelli E, Gruss P, Mallamaci A. Emx2 and Pax6 control regionalization of the pre-neuronogenic cortical primordium. Cereb Cortex. 2002 Feb;12(2):129-39. [Erratum in: Cereb Cortex. 2012 Jan;22(1):243.]

Muzio L, Mallamaci A. Emx1, emx2 and pax6 in specification, regionalization and arealization of the cerebral cortex. Cereb Cortex. 2003 Jun;13(6):641-7.

Nieuwenhuys R. Morphogenesis and General Structure. In: Nieuwenhuys R, ten Donkelaar HJ, Nicholson C, editors. The Central Nervous System of Vertebrates. Berlin: Springer; 1998a. Vol. 1, p. 160-228.

Nieuwenhuys R. Histogenesis. In: Nieuwenhuys $\mathrm{R}$, ten Donkelaar HJ, Nicholson C, editors. The Central Nervous System of Vertebrates. Berlin: Springer; 1998b. Vol. 1, pp. 229-71.

Nieuwenhuys R. Comparative Neuroanatomy: Place, Principles and Programme. In: Nieuwenhuys R, ten Donkelaar HJ, Nicholson C, editors. The Central Nervous System of Vertebrates. Berlin: Springer; 1998c. Vol. 1, p. 273-326.

Nieuwenhuys R. Principles of current vertebrate neuromorphology. Brain Behav Evol. 2017; 90(2):117-30. 
Nieuwenhuys R, Puelles L. Towards a New Neuromorphology. Heidelberg: Springer; 2016. https://doi.org/10.1007/978-3-319-25693-1.

Northcutt RG, Kaas JH. The emergence and evolution of mammalian neocortex. Trends Neurosci. 1995 Sep;18(9):373-9.

Northcutt RG. Evolution of centralized nervous systems: two schools of evolutionary thought. Proc Natl Acad Sci U S A. 2012;109 Suppl 1:10626-33.

Osório J, Mueller T, Rétaux S, Vernier P, Wullimann MF. Phylotypic expression of the bHLH genes Neurogenin2, Neurod, and Mash1 in the mouse embryonic forebrain. J Comp Neurol. 2010 Mar;518(6):851-71.

Pattabiraman K, Golonzhka O, Lindtner S, Nord AS, Taher L, Hoch R, et al. Transcriptional regulation of enhancers active in protodomains of the developing cerebral cortex. Neuron. 2014 Jun;82(5):989-1003.

Peter IS, Davidson EH. Evolution of gene regulatory networks controlling body plan development. Cell. 2011 Mar;144(6):970-85.

Peukert D, Weber S, Lumsden A, Scholpp S. Lhx2 and Lhx9 determine neuronal differentiation and compartition in the caudal forebrain by regulating Wnt signaling. PLoS Biol. 2011 Dec;9(12):e1001218.

Pfenning AR, Hara E, Whitney O, Rivas MV, Wang R, Roulhac PL, et al. Convergent transcriptional specializations in the brains of humans and song-learning birds. Science. 2014 Dec;346(6215):1256846.

Porter BA, Mueller T. The zebrafish amygdaloid complex - functional ground plan, molecular delineation, and everted topology. Front Neurosci. 2020 Jul;14:608.

Porter FD, Drago J, Xu Y, Cheema SS, Wassif C, Huang SP, et al. Lhx2, a LIM homeobox gene, is required for eye, forebrain, and definitive erythrocyte development. Development. 1997 Aug;124(15):2935-44.

Preuss TM. Taking the measure of diversity: comparative alternatives to the model-animal paradigm in cortical neuroscience. Brain Behav Evol. 2000 Jun;55(6):287-99.

Puelles L. Thoughts on the development, structure and evolution of the mammalian and avian telencephalic pallium. Philos Trans R Soc Lond B Biol Sci. 2001 Oct;356(1414):1583-98.

Puelles L. Forebrain Development: Prosomere Model. In: Squire LR, editor. Encyclopedia of Neuroscience. San Diego: Elsevier Academic Press; 2009. Vol. 4, p. 315-9.

Puelles L. Development and Evolution of the Claustrum. In: Smythies JR, Edelstein LR, Ramachandran VS, editors. The Claustrum, Structural, Functional, and Clinical Neuroscience. Cambridge: Academic Press; 2014. p. $119-62$.

Puelles L. Comments on the Updated Tetrapartite Pallium Model in the Mouse and Chick, Featuring a Homologous Claustro-Insular Complex. Brain Behav Evol. 2017;90(2):171-89.

Puelles L. Current status of the hypothesis of a claustro-insular homolog in sauropsids. Brain Behav Evol. Forthcoming 2021.
Puelles L, Alonso A, García-Calero E, Martínezde-la-Torre M. Concentric ring topology of mammalian cortical sectors and relevance for patterning studies. J Comp Neurol. 2019a Jul; 527(10):1731-52.

Puelles L, Amat JA, Martinez-de-la-Torre M. Segment-related, mosaic neurogenetic pattern in the forebrain and mesencephalon of early chick embryos: I. Topography of AChE-positive neuroblasts up to stage HH18. J Comp Neurol. 1987 Dec;266(2):247-68.

Puelles L, Ayad A, Alonso A, Sandoval JE, MartÍnez-de-la-Torre M, Medina L, et al. Selective early expression of the orphan nuclear receptor Nr4a2 identifies the claustrum homolog in the avian mesopallium: impact on sauropsidian/mammalian pallium comparisons. Comp Neurol. 2016a Feb;524(3):665-703.

Puelles L, Ferran JL. Concept of neural genoarchitecture and its genomic fundament. Front Neuroanat. 2012 Nov;6:47.

Puelles L, Kuwana E, Puelles E, Bulfone A, Shimamura K, Keleher J, et al. Pallial and subpallial derivatives in the embryonic chick and mouse telencephalon, traced by the expression of the genes Dlx-2, Emx-1, Nkx-2.1, Pax-6, and Tbr-1. J Comp Neurol. 2000 Aug;424(3):409-38.

Puelles L, Martínez-de-la-Torre M, Bardet S, Rubenstein JL. Hypothalamus. In: Watson C, Paxinos G, Puelles L, editors. The Mouse Nervous System. Amsterdam: Elsevier-Academic Press; 2012. p. 221-311.

Puelles L, Martínez-de-la-Torre M, Martínez S, Watson C, Paxinos G. The Chick Brain in Stereotaxic Coordinates and Alternate Stains. Featuring Neuromeric Divisions and Mammalian Homologies. 2nd ed. Amsterdam: Elsevier-Academic Press; 2019b.

Puelles L, Martínez-de-la-Torre M, Paxinos G, Watson C, Martínez S. The Chick Brain in Stereotaxic Coordinates. An Atlas featuring Neuromeric Subdivisions and Mammalian Homologies. Amsterdam: Elsevier-Academic Press; 2007.

Puelles L, Medina L. Field homology as a way to reconcile genetic and developmental variability with adult homology. Brain Res Bull. 2002 Feb-Mar;57(3-4):243-55.

Puelles L, Medina L, Borello U, Legaz I, Teissier A, Pierani A, Rubenstein JL. Radial derivatives of the mouse ventral pallium traced with Dbx1-LacZ reporters. J Chem Neuroanat. 2016b;75(Pt A):2-19.

Puelles L, Rubenstein JL. Expression patterns of homeobox and other putative regulatory genes in the embryonic mouse forebrain suggest a neuromeric organization. Trends Neurosci. 1993 Nov;16(11):472-9.

Puelles L, Rubenstein JL. Forebrain gene expression domains and the evolving prosomeric model. Trends Neurosci. 2003 Sep;26(9):46976.

Puelles L, Rubenstein JL. A new scenario of hypothalamic organization: rationale of new hypotheses introduced in the updated prosomeric model. Front Neuroanat. 2015 Mar; 9:27.
Puelles L, Sandoval JE, Ayad A, del Corral R, Alonso A, Ferran JL, et al. The pallium in reptiles and birds in the light of the updated tetrapartite pallium model. In: Kaas JH, editor. Evolution of Nervous Systems. 2nd ed. Oxford: Elsevier; 2017. Vol. 1, p. 519-55.

Quintana-Urzainqui I, Rodríguez-Moldes I, Mazan S, Candal E. Tangential migratory pathways of subpallial origin in the embryonic telencephalon of sharks: evolutionary implications. Brain Struct Funct. 2015 Sep;220(5): 2905-26.

Quintana-Urzainqui I, Sueiro C, Carrera I, Ferreiro-Galve S, Santos-Durán G, Pose-Méndez $S$, et al. Contributions of developmental studies in the dogfish Scyliorhinus canicula to the brain anatomy of elasmobranchs: insights on the basal ganglia. Brain Behav Evol. 2012; $80(2): 127-41$

Reiner A. Neurotransmitter organization and connections of turtle cortex: implications for the evolution of mammalian isocortex. Comp Biochem Physiol Part A Physiol. 1993 Apr; 104(4):735-48.

Reiner A, Perkel DJ, Bruce LL, Butler AB, Csillag A, Kuenzel W, et al; Avian Brain Nomenclature Forum. Revised nomenclature for avian telencephalon and some related brainstem nuclei. J Comp Neurol. 2004 May;473(3):377414. [Erratum in: J Comp Neurol. 2004; 475(2):288.]

Reiner A, Yang M, Cagle MC, Honig MG. Localization of cerebellin-2 in late embryonic chicken brain: implications for a role in synapse formation and for brain evolution. J Comp Neurol. 2011 Aug;519(11):2225-51.

Rendahl H. Embryologische und morphologische Studien über das Zwischenhirn beim Huhn. Acta Zool. 1924;5(1-2):241-344.

Ruiz-Ortiz J, Tollkuhn J. Specificity in sociogenomics: identifying causal relationships between genes and behavior. Horm Behav. 2021 Jan; 127:104882.

Shimamura K, Hartigan DJ, Martinez S, Puelles L, Rubenstein JL. Longitudinal organization of the anterior neural plate and neural tube. Development. 1995 Dec;121(12):3923-33.

Shimamura K, Martinez S, Puelles L, Rubenstein JL. Patterns of gene expression in the neural plate and neural tube subdivide the embryonic forebrain into transverse and longitudinal domains. Dev Neurosci. 1997;19(1):8896.

Stacho M, Herold C, Rook N, Wagner H, Axer M, Amunts K, et al. A cortex-like canonical circuit in the avian forebrain. Science. 2020 Sep;369(6511):eabc5534. https://doi.org/ 10.1126/science.abc5534.

Striedter GF, Belgard TG, Chen CC, Davis FP, Finlay BL, Güntürkün $\mathrm{O}$, et al. NSF workshop report: discovering general principles of nervous system organization by comparing brain maps across species. Brain Behav Evol. 2014;83(1):1-8.

Striedter GF. The telencephalon of tetrapods in evolution. Brain Behav Evol. 1997;49(4):179_ 213. 
Striedter GF. Principles of brain evolution. Sunderland: Sinauer Associates; 2005.

Striedter GF. Variation across Species and Levels: Implications for Model Species Research. Brain Behav Evol. 2019;93(2-3):57-69.

Striedter GF, Marchant TA, Beydler S. The "neostriatum" develops as part of the lateral palliuminbirds.JNeurosci.1998Aug;18(15):583949.

Striedter GF, Northcutt RG. Brains Through Time. A Natural History of Vertebrates. New York: Oxford University Press; 2020.

Sugahara F, Pascual-Anaya J, Oisi Y, Kuraku S, Aota S, Adachi N, et al. Evidence from cyclostomes for complex regionalization of the ancestral vertebrate brain. Nature. 2016 Mar; 531(7592):97-100.

Suzuki IK, Kawasaki T, Gojobori T, Hirata T. The temporal sequence of the mammalian neocortical neurogenetic program drives mediolateral pattern in the chick pallium. Dev Cell. 2012 Apr;22(4):863-70.
Tang K, Rubenstein JL, Tsai SY, Tsai MJ. COUPTFII controls amygdala patterning by regulating neuropilin expression. Development. 2012 May;139(9):1630-9.

Tole S, Remedios R, Saha B, Stoykova A. Selective requirement of Pax6, but not Emx2, in the specification and development of several nuclei of the amygdaloid complex. J Neurosci. 2005 Mar;25(10):2753-60.

Tosches MA, Yamawaki TM, Naumann RK, Jacobi AA, Tushev G, Laurent G. Evolution of pallium, hippocampus, and cortical cell types revealed by single-cell transcriptomics in reptiles. Science. 2018 May;360(6391):881-8.

Vaage S. The segmentation of the primitive neural tube in chick embryos (Gallus domesticus). A morphological, histochemical and autoradiographical investigation. Ergeb Anat Entwicklungsgesch. 1969;41(3):3-87.

Whittington CM, Griffith OW, Qi W, Thompson MB, Wilson AB. Seahorse Brood Pouch Transcriptome Reveals Common Genes Associated with Vertebrate Pregnancy. Mol Biol Evol. 2015 Dec;32(12):3114-31.
Wullimann MF, Mueller T. Expression of Zash1a in the postembryonic zebrafish brain allows comparison to mouse Mash1 domains. Gene Expr Patterns. 2002 Oct;1(3-4):187-92.

Wullimann MF, Mueller T. Teleostean and mammalian forebrains contrasted: evidence from genes to behavior. J Comp Neurol. 2004 Jul;475(2):143-62. [Erratum in: J Comp Neurol. 2004;478:4].

Wullimann MF, Rink E, Vernier P, Schlosser G. Secondary neurogenesis in the brain of the African clawed frog, Xenopus laevis, as revealed by PCNA, Delta-1, Neurogenin-related-1, and NeuroD expression. J Comp Neurol. 2005 Aug;489(3):387-402.

Yun K, Potter S, Rubenstein JL. Gsh2 and Pax6 play complementary roles in dorsoventral patterning of the mammalian telencephalon. Development. 2001 Jan;128(2):193-205. 